LARORatorio

LABORatorio R. Revelli

Centre for Employment Studies

\title{
Estimating Poverty Persistence In Britain
}

\author{
Francesco Devicienti
}

Working Papers Series

No. 1 


\title{
Estimating Poverty Persistence In Britain
}

\author{
Francesco Devicienti*
}

\begin{abstract}
This paper uses longitudinal data from the BHPS, waves 1-8, to document low-income dynamics and persistence for individuals living in Britain in the 1990s. Poverty exit and reentry rates are estimated and the resulting distribution of time spent in poverty is calculated, both in single and in multiple-spells frameworks. Poverty persistence predictions are also produced for various subgroups of the populations. To do this, I estimate a multiple-spell model of transitions in and out of poverty, controlling for observed and correlated unobserved individual heterogeneity and for a potential initial condition problem. Components-of-variance models are also used to predict the number of years in poverty for the targeted groups. The two sets of predictions are then compared.
\end{abstract}

Keywords: poverty persistence, hazard models, multiple spells, unobserved heterogeneity, variance-components models.

JEL classification: I32, C33, C41

* LABORatorio Riccardo Revelli, Centre for Employment Studies, via Real Collegio 30, 10124 Moncalieri (To), Italy, and ISER, Institute for Social and Economic Research, University of Essex, UK. E-mail: fdevic@labor-torino.it. This paper forms part of the research programme of the TMR network Living Standards, Inequality and Taxation [Contract No. ERBFMRXCT 980248] of the European Communities whose financial support is gratefully acknowledged. For helpful comments I owe many thanks to Stephen Jenkins, Chris Flinn, John Ermisch, Marco Francesconi, David Card and Lorenzo Cappellari. Lorenzo also kindly provided me with his programs for the variance-components models estimation. I alone am responsible for all remaining errors and omissions. 


\section{INTRODUCTION}

In recent years, income dynamics and poverty persistence have increasingly been regarded in public and academic discussions as important social indicators to be placed alongside information about the income distribution at a point in time. It has been recognised that a better measurement and understanding of the poverty problem can be achieved if traditional research based on cross-sectional data is complemented by longitudinal analyses. In the latter perspective what becomes relevant is the pattern of income changes, from one year to the next, for each person in the population, and this is the focus of the present paper.

When household net income falls below a minimum needs standard, current resources are insufficient to meet basic needs and the household members are deemed as being in poverty. When this state of deprivation is persistent, so that some individuals tend to be poor over much of their lifetime, societies become naturally concerned about its long-run effects. Not only any vision of social justice would condemn a poverty curse that sticks over the same group of individuals from one year to the other, rather than being a phenomenon that, if anything, strikes randomly and in a temporary way. Efficiency considerations and political stability can be invoked as well, as additional good reasons of concern of persistent poverty in both developed and underdeveloped countries. Furthermore, examining the extent of low income persistence is important in providing information to the design and implementation of poverty alleviating and anti-poverty programmes. The former type of programmes provides assistance to those in poverty through various forms of cash transfers and it is clearly important to document the extent to which individuals with certain characteristics remain in poverty, and so continue to be eligible for public assistance, year after year. As far as anti-poverty policy measures are concerned, their design should depend on whether poverty is a short-duration event, which most people experience at one time, or a long-duration event concentrated amongst particular identifiable groups in the population.

This paper intends to document and predict poverty persistence in Britain, using longitudinal data from the British Household Panel Survey (BHPS), waves 1-8. The basic questions that $I$ intend to address are: How long will an individual falling into poverty spend below the poverty line? How important are multiple episodes of poverty for the same 
individual for a correct measuring of poverty persistence? What individual/household socio-economic characteristics are relevant in "explaining" and predicting the poverty dynamics observed in 1990s Britain?

The paper contributes to the existing literature in two ways. It provides first estimates for Britain of the total time that different types of individual spend below the poverty line over a long period of time (eight years in this case). The paper shows that it is essential to model multiple spells of poverty to do this, and that the most commonly used models based on single poverty spells - are inadequate.

The second contribution of the paper is to provide a comparison of two alternative approaches for modelling poverty persistence, and hence a methodological robustness check. The first approach is based on hazard-rate models, controlling for observed and unobserved heterogeneity. Unobserved individual-specific factors leading to exit from poverty and factors affecting re-entry into it are allowed to be correlated. The paper also controls for a potential "initial condition problem". If unobserved factors are important, then whether the first non-left censored spell observed in the panel is a poverty or a nonpoverty spell is potentially endogenous. The second approach is based on variancecomponents models of the time series of income. In both approaches, estimated parameters are used to derive poverty persistence predictions for individuals with differing characteristics.

The methods used are a development of those used by Stevens (1999) in her study of poverty dynamics in the USA. The current paper's methods and focus differ from earlier research on poverty dynamics in Britain. See, for example, Jarvis and Jenkins (1997), Jenkins (2000) and Devicienti (2002a). All use data from the BHPS, respectively the first 4 waves, the first 6 , and the first seven waves and provide descriptive evidence of poverty in Britain from a longitudinal perspective. Jarvis \& Jenkins (1997) use life-table estimates of exit and re-entry rates to calculate the distribution of time spent below the poverty line in the next three interviews. They also employed various cross-tabulation techniques to investigate the association between poverty transitions and various labour-market and demographic "trigger events". Devicienti (2001) used a longer observation window and calculated the distribution of time poor over the next six interviews. Proportional hazard models for poverty exit and re-entry rates were employed in order to estimate poverty 
persistence in different groups of the population. Poverty exit and re-entry rates regressions were estimated separately, without controlling for unobserved heterogeneity.

The models of the present paper differ from other hazard-rate applications as exit and re-entry rates are estimated simultaneously, observed heterogeneity, unobserved heterogeneity and the initial condition are explicitly controlled for, and multiple-spell poverty persistence measures are computed for targeted population groups. More recently, Cappellari and Jenkins (2002a, b) estimated a first order Markov model of poverty transitions, controlling for the potential endogeneity of the base-year poverty status (initial condition) and for income retention between consecutive pairs of interviews (attrition). The hazard and covariance structure models used in this paper complement the Markovian model of Cappellari and Jenkins. While their modelling strategy may be better placed for analysing true state dependence, their first order Markov assumption is more restrictive in terms of the underlying model dynamic.

This paper is organised as follows. Section 2 describes the data and definitions adopted in my analyses. Section 3 provides a brief description of poverty dynamics and persistence in Britain, comparing the cross-sectional perspective with the longitudinal one. Simple life table estimates of exit rates and re-entry rates are provided first, and then used to derive the distribution of time in poverty over single and multiple spells. My modelling strategy with the hazard rate models is explained in section 4 , which also discusses the results obtained and the simulations of poverty persistence for selected types of individual. The same is done in section 5 when the alternative modelling approach provided by the variancecomponents models is followed. Section 6 concludes the paper. Tables containing my results are collected in the Appendix at the end of the paper.

\section{DATA AND DEFINITIONS}

For my analysis, I use data from the BHPS, waves 1-8 (survey years 1991-8). The first wave of the BHPS was designed as a nationally representative sample of Great Britain living in private households in 1991. First wave interviews were carried out in autumn 1991 and household interviewed were selected by an equal probability sampling mechanism. ${ }^{1}$ The achieved sample comprised about 5,000 households, which correspond to a response 
rate of about 65 per cent of effective sample size. At wave 1, over 90 per cent of eligible adults (approximately 10,000 individuals) provided full interviews. Original sample respondents have been followed and reinterviewed at approximately one-year intervals subsequently. Children in original sample households are also interviewed when they reach the age of sixteen. The sample therefore remains broadly representative of the British population as it changes through the decade. The wave-on-wave response rate was about 88 per cent for wave 1 to wave 2, and over 90 per cent thereafter.

As in this paper I am ultimately interested in the deprivation suffered by the individuals, I take the individual - not their household - as the unit of analysis. This is necessary for allowing the individual to move from one household situation to another over time. However, individuals live in families, where they share resources and various economic and demographic events. It becomes then natural to refer to the household's total financial resources in order to assess the living standards of each of its members. For this reason, I attribute to each person the net income of the household to which s/he belongs (equal pooling and sharing of income within households). These assumptions are also made in the papers on poverty dynamics in the UK and US mentioned above.

The household income variable available in the official BHPS release files is prior to the deduction of taxation and social insurance contribution. For my analysis, a more appropriate proxy for individual well-being is represented by the net income of the individual's household, divided by an equivalence scale in order to account for different household sizes and compositions. Net household income variables have been recently provided by Bardasi, Jenkins and Rigg (1999), as an unofficial supplement to the BHPS data and I have used these in the present paper. ${ }^{2}$ The time period over which income is measured is the year, and in particular refers to the 12-month interval up to September 1 of the year of the relevant interview year. ${ }^{3}$ All incomes have been converted to January 1998 prices so as to carry out comparisons in real terms. Incomes are made 'equivalent' by

\footnotetext{
${ }^{1}$ For a detailed discussion of the BHPS methodology, representatives, and weighting and imputation procedures, see Taylor (1994) and Taylor (1998).

${ }^{2}$ The components of net income are the same as that adopted by the British Department of Social Security (DSS) in its low income statistics (Department of Social Security, 1999). See Bardasi et al., 1999.

${ }^{3}$ The DSS uses current income (i.e. referring to the month prior to the interview) instead of annual income. Böheim and Jenkins (2000) conclude that the two measures provide a remarkably similar picture of the Britain's income distribution and its trends.
} 
deflating them with the 'McClements Before Housing Costs' equivalence scale rate, which has a semi-official status in UK distributional analyses. ${ }^{4}$

I assume that an individual is "poor" if his/her 'needs-adjusted household net income' is less than a chosen poverty line. Two alternative low-income cut-offs have been selected, reflecting the relevance of both a notion of "absolute" and a notion of "relative" poverty. As an absolute poverty line I have chosen to use half Wave 1 mean income. The relative poverty line is defined as half contemporaneous mean income. Although these may be seen as arbitrary choices, their use has become common practice in the UK (e.g., Jarvis and Jenkins, 1997; Jenkins, 2000) and I use them also to facilitate comparisons with earlier work on poverty dynamics.

To each poverty and non-poverty spell experienced by a sample member, I have attached a vector of demographic and labour market characteristics. These may be timevarying. For transitions occurred between time $t$ and time $t+1$, covariates refer to the value that the relevant characteristics assume at time $t$. In addition, I have matched in the unemployment rate in each individual's travel-to-work area to provide information on local labour market conditions. ${ }^{5}$

All persons (adults and children) are included in the analysis in each year in which they are present in the sample, including those who leave prior to the end of the survey. The unbalanced panel that I use for my preliminary analysis (Table 1 and 2) is composed by 16,531 individuals, which give a total of 85,199 person-years. Children are defined as persons aged 16 or less at the current interview. In my sample children represent about 27 per cent of the total number of persons. ${ }^{6}$ From this data set, I then derive poverty and outof-poverty spells for each person. After excluding all left-censored spells, i.e. those spells starting prior to the start of the survey in 1991, my final sample consists of 2592 poverty spells and 2522 out-of-poverty spells, when the absolute poverty line is used. Numbers are only slightly higher if the relative poverty line is employed instead (see Tables 3 and 4). ${ }^{7}$

\footnotetext{
${ }^{4}$ In the 'McClements Before Housing Costs' equivalence scale, the scale rate for a childless married couple is equal to 1.0 ; single householder 0.61; rates also vary by children's age (see Department of Social Security, 1999, for details).

${ }^{5}$ The local market information is taken from the National Online Manpower Information Service (NOMIS), and is matched to the BHPS by date of interview and travel-to-work area.

${ }_{7}^{6}$ Age is measured at the individual's first interview for this calculation only.

${ }^{7}$ Computing the spell length is however complicated by the fact that some individuals may temporarily exit from the panel. If there are numerous gaps in their panel participation, I cannot compute the exact length of
} 


\section{STATIC VERSUS DYNAMIC POVERTY PERSPECTIVES: EVIDENCE FOR BRITAIN}

\subsection{Preliminary descriptive analysis}

Table 1 provides a standard cross-sectional perspective on changes in the distribution of needs-adjusted household income in Britain during the 1990s, derived from the BHPS. Over this period, average income rose on average by about 11 per cent and, partially reflecting this, the proportion of individuals with income below the absolute poverty line has decreased, at least from 1993 onwards. The number of people below the relative poverty line is, as one might expect, systematically higher than the number below the absolute poverty line after the first wave (in which the two low-income cut-offs coincide). After 1993, the proportion of poor falls also according to the relative threshold, though to a lesser extent. ${ }^{8}$

Although absolute poverty rates at a point of time are on average about $15 \%(17 \%$ with the relative cut-off), much higher is the fraction of the population that had low incomes at one period or another. Table 2, in fact, shows that about one third (32\%) of the sample is touched by absolute poverty at least once (34\% with respect to relative poverty). These figures confirm the well-established fact that the number of people experiencing low income over a period of time is fundamentally different from that at a point in time. When we turn the attention to those persistently in poverty, we notice that only a tiny minority $(0.5-0.7 \%)$ had low income at each of the eight waves while the great majority (68-66\%) has never been poor in the 1991-1998 period. The expected stay in poverty for someone just entering in the panel and who will be interviewed for the next 8 years is only 0.78 years, according to the absolute poverty line. If we consider those who ever become poor, the expected time spent below this income threshold is 2.56 years.

their poverty and non-poverty spells. Moreover, even when the individual's participation to the panel is not interrupted by such gaps, income information may be missing at some interview. Bardasi, Jenkins and Rigg (1999) could in effect not calculate net household income of persons living in households where not all the eligible individuals in the household gave a full interview. In a small number of cases, the presence of more than one missing (or gaps in the panel participation) alternated by valid incomes has implied that the whole sequence had to be discarded. When an individual leaves prior to the end of the survey her on-going spell is treated as right censored. Similarly, for sequences with missing values in the first years but valid spells subsequently, the initial spell is treated as left-censored and discarded but the subsequent ones are kept in. I re-estimated hazard functions and my multivariate models on the sub-sample of individuals with no missings/gaps in their income sequence. Results were unchanged and are not reported.

${ }^{8}$ Over the 1990s inequality in needs-adjusted household net income, as measured by the Gini coefficient, barely changed. It was equal to 0.30 in 1991 and 0.31 thereafter. 
So far I have simply counted the number of waves spent in poverty for the individuals in my data set, but it is well known that this simple descriptive method has an important shortcoming. People who end (or begin) the period in poverty may be starting a long stay in poverty, despite the fact that they appear to be poor only in one or two of the observed years. This leads to an understatement of poverty persistence, since some of those observed to be poor only a short time are actually in the midst of lengthy poverty spells that are censored by the beginning or end of the sample frame. In response to this problem, researchers have devised more appropriate approaches for studying income and poverty dynamics and these have been discussed in some details by Bane and Ellwood (1986), Jenkins (2000) and Stevens (1999). Not only are these more advanced techniques immune to the previous problem, they also lend themselves to a multivariate analysis of the factors that affect transitions in and out of low income. Some of these techniques are employed in the rest of the paper in an attempt to provide a more accurate estimate of the poverty persistence experience of the population as a whole and of particular subgroups of it.

\subsection{Low income exit and re-entry rates}

I start analysing the broad pattern of exit from and returning into poverty by using simple non-parametric estimates of the exit and re-entry rates, and look at how they vary with the length of time people have had in poverty and out of poverty, respectively. The exit rates that are relevant in this context are the ones that refer to a cohort of persons just falling into poverty and hence at risk of exit thereafter. The re-entry rates refer instead to a cohort of persons just starting a spell out of poverty, and so at risk of re-entering. Exit rates are calculated by dividing the number of persons ending a spell after $d$ years in poverty by the total number with low income for at least $d$ waves. Re-entry rates were calculated analogously. Unlike the simple count of number of years in poverty, the spell-approach can easily incorporate right-censored spells. Persons who remain in poverty through the end of the sample contribute to the estimation of the exit rates (thought he denominator of the exit rates) in all years through the censored year. In our 8-wave data set, the exclusion of leftcensored spells implies that only spells just starting in wave 2 or in later waves can be considered. Therefore, exits from the state can occur only at any of the at-most 6 interviews 
following the one in which the individuals is first found in poverty. Including the latter, then, each individual can be observed between 1 or at most 7 interviews in poverty.

Table 3 shows the exit rates from poverty, where the latter is defined using the absolute low-income threshold in panel (a) and the relative threshold in panel (b). Re-entry rates are illustrated in Table 4. According to both tables and both poverty lines, estimated hazard rates show evidence of negative duration dependence: the longer an individual stays in poverty (out-of-poverty) the less likely it is that s/he will leave that state in the next period. Table 3(a) reports that, for the cohort of individuals just starting a poverty spell, the probability of leaving after the first year is equal to one half; after four years is only 22 per cent. In panel (b), one notes that chances of climbing out of relative poverty are systematically lower than from absolute poverty. This is because, as mean income grows, it is easier to cross the poverty line if this is fixed in real terms.

Re-entry rates are smaller than exit rates and show a slower decline. Indeed, the estimates reported in Table 4(a) point to a significant risk for individuals out of poverty to fall back below the poverty line, particularly so in the years just after an exit from poverty. ${ }^{9}$ About $29 \%$ of the individuals ending a poverty spell will again have income below the poverty line after the first year; within four years, $52 \%$ of the poverty escapers will have fallen back in poverty. The hazards of re-entry are even higher in panel (b), where the relative poverty line is employed. In this case, the re-entry rate after one year rises at 32 per cent, and after 4 years 57 per cent will have returned in low income. Overall these figures suggest that the extent of low-income turnover is quite high. Although there is a small group of people who are persistently poor, there is a relatively large number of poverty escapers and entrants from one year to the next.

When I compare my findings with those obtained by Stevens (1999) for the US I discover surprisingly close similarities in the reported estimates. For example the chance of leaving poverty after one (four) year(s) has been estimated at $0.50(0.22)$ in my Table 3(a) while the corresponding figure in Stevens is $0.53(0.24)$. The same holds for re-entry rates, where at duration 1 and 2 values in my Table 4(a) are 0.29 and 0.16 , respectively, while the corresponding figures in Stevens are 0.27 and 0.16 . One may therefore be tempted to

\footnotetext{
${ }^{9}$ In theory one could also estimate rates for first entry (as opposed to re-entry) into poverty. But estimating first entry would require that I observe individuals from birth forward to identify their initial entry into poverty.
} 
conclude that there is some evidence that the poverty turnover in the UK is not very different than that experienced in the US. However, one should keep in mind that - a part from the intrinsic difficulties in comparing income and poverty definitions - the time periods covered by the two studies are different: the 1990s for the UK and the 1970s and 1980s for the US.

\subsection{Poverty persistence over single and multiple spells}

The pictures emerging from the estimated exit and re-entry rates can be brought together in order to derive the 'distribution of time spent poor' over multiple spells, a fundamental measure of poverty persistence. ${ }^{10}$ For instance, suppose that a 8 -wave income sequence like $(N, P, P, N, N, N, P, P)$ has been observed, where a $P$ at rank $i$ th denotes lowincome at year $i$ and an $N$ denotes out-of-poverty. Over the entire time period, the individual represented in that sequence had 4 years in poverty. Denote with $e(d)$ and $r(d)$, respectively, the exit and re-entry rates at duration $d$. Excluding the first left-censored nonpoverty spell, the probability of that sequence can be found as the product of the probability of the constituent spells:

$$
\operatorname{Prob}(P, P, N, N, N, P, P)=[1-e(1)] e(2)[1-r(1)][(1-r(2)] r(3)[1-e(1)] .
$$

To compute the probability of observing 4 out of 7 years in poverty, one then needs to obtain the probabilities of all possible sequences that generate a total of four years in poverty and sum them up. This is how the probabilities reported in columns three and six of Table 5 are computed. ${ }^{11}$ The second and fifth columns of Table 5 show the distribution of years spent poor in single spells of poverty, calculated using only the exit rates, i.e. not taking multiple spells into account. ${ }^{12}$ Column three and six on the contrary use both exit and re-entry rates to estimate years spent poor over individuals' lifetime. As a way of comparing predictions based on the single and the multiple spell approach, I have computed the distribution of 'time spent poor' emerging from the actual patterns observed in the panel

\footnotetext{
${ }^{10}$ Devicienti (2001) uses the first 7 waves of the BHPS to assess poverty persistence and also discusses results sensitivity to the definition of transitions in and out of poverty, namely the practice followed in some papers (Jenkins, 2000; Bane and Ellwood, 1986; Duncan et al., 1984) of considering a transition out/in poverty only if the poverty line is crossed over by at least $10 \%$ of its value.

${ }^{11}$ See also Stevens (1999), Devicienti (2001) or Jarvis and Jenkins (1997).

${ }^{12}$ In a single spell approach, the only event giving rise to 4 years in poverty is $(N, P, P, P, P, N, x), x=P, N$, which has probability $[1-e(1)][1-e(2)][1-e(3)] e(4)$.
} 
data. In particular, column 4 derives from a simple count the interviews in poverty for the wave 2 low-income entry cohort - sequences $(N, P, x, x, x, x, x, x)$, where $x=N, P$.

Look now at the results presented in Table 5. Comparing columns 2 and 3 (or columns 5 and 6), we can see that there is clear evidence that the single-spell approach estimates a distribution of 'time spent poor' in which a larger proportion of the population experiences short stays in poverty. For example, $50 \%$ of the population will have income below the absolute poverty line in only one interview (out of the next seven) according to the single spell approach. However, allowing for repeated spells the figure decreases to only $22 \%$ in column 3. The percentage obtained from the actual patterns observed (column 4), is $18 \%$. At longer duration, on the other hand, the single spell approach tends to underestimate the distribution of time spent poor, while a repeated spell approach does a good job in replicating observed patterns. For example, $41 \%$ will spend at least 4 years below the absolute poverty line if repeated spells are accounted for, while only $19 \%$ is the corresponding figure in a single-spell predicting framework. The actual proportion in the sample that spent at least four interviews in poverty is $45 \%$, when the absolute low-income threshold is considered. It is striking how much better the repeated-spell approach provides predictions of poverty persistence, and that is true for the relative poverty line as well.

However even predictions based on the multiple-spell approach tend to overestimate the proportion of individuals who spend only one year in poverty and to underestimate the proportion of those who remain in poverty for longer duration. Moreover the previous analysis assumed that all the observed spells refer to a completely homogeneous population. It is instead more likely that individuals with particular observable and unobservable characteristics face different risks of exiting from and re-entering into poverty, and therefore of being persistently poor. To improve upon the previous predictions, I now move from the simple life-table estimates presented so far to multivariate techniques that allow exit and re-entry rates to depend on important socio-economic correlates of poverty transitions.

\section{MODELLING POVERTY EXIT AND RE-ENTRY RATES: A MULTIVARIATE APPROACH}




\subsection{Separate exit and re-entry rates regressions}

Each individual is recorded in the data as having experienced either a single type of spell (poverty or out-of poverty) or both. In the latter case, it is possible that the person might have gone through repeated spells of poverty and/or repeated spells of non-poverty. In order to establish the broad patterns of poverty exit and re-entry when individual and household controls are introduced in the analysis, I first pool all the spells of a given type and estimate two separate regressions: one for the chances of leaving poverty and the other for the hazard to re-enter into it. I employ discrete-time hazard rate models. In particular, let us consider a group of people that have just entered in a state (at $d=0$ ) and are at risk of exiting thereafter, at each exit time measured by the (discrete) duration variable $d, d$ $=1,2, . ., D$. The probability that a person $i$ leaves the state at duration $d$, given that has survived in the state to $d-1$, is assumed here to be a standard logit hazard function:

$$
h_{i t}(d)=\frac{\left.\exp \left[\alpha(d)+X_{i t}^{\prime} \beta\right)\right]}{\left.1+\exp \left[\alpha(d)+X_{i t}^{\prime} \beta\right)\right]}
$$

In (1) $X_{i t}$ is a set of covariates that differ across individuals and, potentially, also over calendar time (represented by $t$ ). These covariates can be fixed or time-variant; in the latter case they are supposed to be constant within the time-interval represented by duration $d$. The dependence of the hazard upon duration in the spell $d$ is explicitly emphasised by (1), while dependence upon $X_{i t}$ - and through $X_{i t}$ upon calendar time $t$ - is left implicit so as simplify notation. $\beta$ is a vector of parameters to be estimated and $\alpha(d)$ is some functional form of how duration of the spell affects the hazard rate. As assumptions on the form of the baseline function $\alpha(d)$ can potentially bias the parameter estimates, it is important to allow for fairly general specifications. Rather than assuming any particular distribution for the underlying true duration, here I will use a fully flexible non-parametric specification (Meyer, 1990) with interval specific dummies for the baseline hazard.

With the data organised in person-year format, estimation of the model parameters is particularly easy, being implemented with standard packages for dichotomous dependentvariable models (see Allison 1982, Jenkins 1995). One simply needs to consider the relevant cohorts: those just starting a poverty spell, for the estimation of the exit rates, and those just starting an out-of-poverty spell, for the estimation of the re-entry rates. 


\subsection{Incorporating unobserved heterogeneity and correlation across spells}

\subsubsection{A joint maximum likelihood estimation of exit and re-entry rates}

It is well known that ignoring unobserved heterogeneity can lead to serious misspecification, that can result in underestimation of how the hazard rate changes with duration and bias the effect of the covariates on the hazard rate (e.g. Kiefer, 1988). Unobserved heterogeneity may be entered in the specification of the hazard rate as an individual-specific additive error term, constant over time. When a distribution is assumed for such an error term, one can write the individuals' likelihood function contributions conditional on a particular value of the error term and integrate over all possible values, so as to obtain the unconditional individual contribution. The parameters of the unobserved heterogeneity distribution are jointly estimated with those contained in $\beta$ and $\alpha(d)$.

The simple hazard rate models outlined above for the separate estimation of exit and re-entry rates not only do not incorporate unobserved heterogeneity, but also assume in effect that the multiple spells in a given state that an individual experiences are not correlated. Moreover, spells in the two alternating states (poverty and non-poverty) for the same individual are also assumed to be uncorrelated. In the absence of unobserved individual heterogeneity, these assumptions might be reasonable and each spell in and out of poverty can be treated as conditionally independent. In this case, the likelihood functions for the two types of spells can be maximised separately (e.g., Lancaster, 1990). However, when individuals differ in unobserved terms like ability, effort, tastes, and these unobservables remain constant over the individual's lifetime, the assumption of uncorrelated spells might be inappropriate. People that have had long stays in poverty in the past might be more likely to experience long spells again, particularly so if it is some of their unobservable characteristics mainly responsible for their long survival in the state. Similarly, individuals that spent a long time out of poverty in the past might be less likely to experience long spells of low income in the future. At first sight, a simple test for correlation with previous poverty spells might be to include the length of previous spells into the exit rate regression, and estimate over the subsample of those experiencing multiple spells. A direct method to test for correlation between current spells of one type with past spells of the other type is instead to include the length of the previous spell of the other 
type. ${ }^{13}$ However, the length of previous spells is likely to be correlated with the random unobserved heterogeneity terms, so that estimated coefficients are inconsistent.

A more satisfactory way to model correlation across spells in the presence of unobserved heterogeneity is through a joint maximum likelihood estimation of exit and reentry rates, in which the hazard rates depend on spell-specific unobserved heterogeneity terms and these terms are correlated across spells (Stevens (1999), Meghir and Whitehouse (1997), Ham and LaLonde (1996)). The hazard rate at duration $d$ for an individual $i$ is specified as in the discrete logit model, but is now conditional to an individual-specific and state-specific effect. For poverty spells this hazard is given by:

$$
E_{i}\left(d \mid \theta_{i}^{P}\right)=\frac{\left.\exp \left[\theta_{i}^{P}+\alpha_{d}^{P}+X_{i t}^{P \prime} \beta^{P}\right)\right]}{\left.1+\exp \left[\theta_{i}^{P}+\alpha_{d}^{P}+X_{i t}^{P^{\prime}} \beta^{P}\right)\right]}
$$

where $\theta_{i}^{P}$ is an individual-specific effect common across all poverty spells of individual $i$ and $d$ refers to duration in the current poverty spell.

For non-poverty spells instead the hazard is denoted by:

$$
B_{i}\left(d \mid \theta_{i}^{N}\right)=\frac{\left.\exp \left[\theta_{i}^{N}+\alpha_{d}^{N}+X_{i t}^{N} \beta^{N}\right)\right]}{\left.1+\exp \left[\theta_{i}^{N}+\alpha_{d}^{N}+X_{i t}^{N \prime} \beta^{N}\right)\right]}
$$

where $\theta_{i}^{N}$ is common across all the non-poverty spells of individual $i$ and $d$ now indicates duration in the current non-poverty spell. Duration dependence is summarised by the interval specific dummies $\alpha_{d}^{P}$ and $\alpha_{d}^{N}$ for poverty and non-poverty spells, respectively. Covariates are collected in the vectors $X^{P}{ }_{i t}$ and $X^{N}{ }_{i t}$, for the two types of spells, respectively.

I allow for temporal correlation across spells of the same type, and also for correlation across spells of different types, by assuming that $\theta^{P}$ and $\theta^{N}$ are jointly distributed. For the model estimation, one can follow two possible routes. The first one is to specify a joint (parametric) distribution $G\left(\theta^{P}, \theta^{N}\right)$ for the unobserved heterogeneity and to integrate out the random effects in the likelihood function that includes both poverty and non-poverty spells for any individual in the data. The alternative is to use the Heckman and Singer (1984) estimator, where the distribution $G\left(\theta^{P}, \theta^{N}\right)$ is left unspecified - so as to minimize misspecification biases - and is approximated by a bivariate discrete distribution with a number of support points to be determined by the data. I follow the latter approach in this

\footnotetext{
${ }^{13}$ Devicienti (2001) includes such controls in some of his models finding some evidence of correlation
} between past and current spells of the same types, and across different types. 
paper, as in Stevens (1999). The technical appendix at the end of the paper contains further explanations.

\subsubsection{Left-censored spells and initial condition}

A potentially important point that deserves attention relates to the exclusion in my hazard rate models of left-censored spells. If unobserved heterogeneity was not a determinant of the hazard rates in the true model, then estimation of exit and re-entry rates only from non-left-censored spells would provide consistent estimates of the parameters of covariates and duration terms (Heckman and Singer, 1984). However, when unobserved heterogeneity is a determinant of the true spell length, then the exclusion of left-censored spells can result in potential biases, as one is likely to oversample individuals characterised by higher transition probabilities than the rest of the population. Some formal methods for introducing left-censored spells exist, even though they are hardly computationally tractable as they require that one 'integrates' over all possible (unobserved) histories up to the starting year in the sample (e.g., Moffitt and Rendall, 1984). In her paper Stevens (1999) used a straightforward method to test how serious is the bias arising from the exclusion of left-censored spells. She had at her disposal a panel with twenty waves, so she could split the overall sample frame in two sub-periods. The first sub-period corresponded to the most recent 10 years and was used for the estimation. The second sub-period corresponded to the initial years of the panel and was only used to calculate the length of the spells that in the first sub-period are left-censored. This way left-censored spells could be included in the shorter panel constituted by the first sub-period. However, the relatively short length of the BHPS does not allow me to do the same exercise.

The alternative method I that have used is to extend my models to include an initial condition equation, as in Meghir and Whitehouse (1997). Whether the first non-left censored spell is of poverty or of non-poverty will depend on individual characteristics including unobserved heterogeneity, creating an initial condition problem whereby the identity of the first fresh spell I observe is endogenous. To control for this potential selection bias I define a probability of being in poverty at the initial point of observation

(first non-left censored spell) of each individual as a function of characteristics and of unobserved heterogeneity $q$, as follows: 


$$
P_{i 0}(q)=\frac{\left.\exp \left[q+W_{i 0}{ }^{\prime} \phi\right)\right]}{\left.1+\exp \left[q+W_{i 0}{ }^{\prime} \phi\right)\right]}
$$

where 0 is used to denote the time in which the first fresh spell started and $W_{i 0}$ is a vector of observables. This probability is then estimated together with the poverty and out-of-poverty transition equations allowing for the unobservables to be correlated, by assuming that $q, \theta^{P}$ and $\theta^{N}$ have a joint trivariate distribution. The procedure is explained in further details in the technical appendix.

\subsection{Who moves out of poverty? Who moves back in? Estimation results}

The various papers that have used the hazard rate approach to the study of poverty dynamics, differ not only in the types of covariates included, but also in the inclusion or exclusion of poverty spells referring to some groups of the population. This is hardly surprising given that, while economic theory provides a unified and well-developed framework for studying earnings and income dynamics, no similar theory exists in the more complicated case of the dynamics of 'net equivalised household income'. As a consequence researchers have to undertake a more empirical approach and justify their modelling choices on intuitive grounds, rather than formal ones. Jenkins (2000) discusses at some depth the various modelling issues arising in empirical research of income mobility and poverty dynamics. $^{14}$

The models I present below were estimated including many individual and household characteristics, as well as variables summarising labour market conditions. In principle a whole variety of factors can be thought of as important determinants of lifetime poverty. Important examples might be the education and sex of the household head, two timevarying covariates that summarise many of the important demographic and economic changes that may affect the welfare of the household members. The number of children and the number of adults present in the household constitute two additional examples. After controlling for these household-level variables, it would be valuable to include individuallevel variables as well, given that ultimately the current household structure is partly the result of the individual's choices. In my models the main individual-level characteristics

\footnotetext{
${ }^{14}$ Devicienti (2001) examines the implications for the estimates of including/excluding spells that refer to children, given that these spells are determined by the parents' socio-economic decisions. Results hardly changed at all.
} 
which was found important is age, which allows me to examine how more at risk the very young and the elderly are from the rest of the population. Other important individual-level controls include race and unemployment rates in the local travel-to-work area. ${ }^{15}$

The results of parsimonious specifications of my models are gathered in Tables 6 . Panel (a) reports the estimates for the poverty exit rate regression, panel b) refer to the reentry rates and panel (c) to the initial condition. Results obtained with the models that do not control for unobserved heterogeneity are shown under the heading "Model 1". By "Model 2" I mean the joint estimation of exit and re-entry rates, allowing for correlated unobserved heterogeneity but not for the initial condition. Including the later as well I obtain the results shown under the heading "Model 3".

Consider first my regressions without unobserved heterogeneity. In this case, data confirm the negative duration dependence already found with the simple life-table estimates of both exit and re-entry regressions in Tables 3 and 4. Household and individual characteristics impact the probabilities of exiting and returning to poverty in predictable ways. Those living in a household whose head has a relatively low level of education (less than A-levels ${ }^{16}$ ) have higher chances of experiencing long spells of poverty than those living with a better educated household head, as exit rates are calculated to be lower and reentry rates higher. The logit coefficient for this variable is 0.15 for the exit regression without unobserved heterogeneity. To translate it into a hazard rate, I substitute that value into (1) and chose the value of the other regressors in such a way that they represent a reference type. For example, a single adult aged 30, with all other variables set to zero, has a hazard rate for leaving poverty after one year of 0.64 if he has A-levels or more, compared to a value of 0.61 if he has lower levels of education. The difference is not impressive, but one should consider that those with highly educated heads have also lower re-entry probabilities (with a coefficient of -0.24 in the re-entry rate regression) and that these differences, though small, tend to cumulate when considering a relatively long time interval. A better assessment of the impact on poverty persistence of selected characteristics

\footnotetext{
${ }^{15}$ A whole set of other influences (e.g., being unemployed just before the start of a poverty spell) are not directly included as they are likely to cause strong endogeneity biases. The models estimated are then interpreted as reduced form models. Note also that the random effect terms are assumed to be uncorrelated with the included regressors.

${ }^{16} \mathrm{~A}$-level is the level of academic achievement often used in Britain as the basis for admission to a university. It generally corresponds to 13 years of schooling.
} 
therefore requires that poverty be measured over a period of time taking entries and exits into account. In the present paper this is achieved through the simulation analysis of section 4.4 .

No significant pattern with respect to age was found for the exit rates, while in the case of re-entry individual age seem to be an important determinant. Considered together, the coefficients of age and age squared indicate that re-entry rates are higher for the very young (about 0.28 at age 0 ) and for the elderly (about 0.29 for those age 75 ), with the minimum (about 0.25 ) for those aged 36.

The presence of children in the household has a negative association with the chances of exiting and a positive effect on the re-entry probabilities. Consequently poverty is a particularly persistent phenomenon for those living in families where the proportion of children over the total number of household members is relatively high. The reasons for higher poverty chances if there are kids are not surprising: many people have children before their earning power has reached its peak; it is hard for parents looking after their kids to work full-time; as household income is adjusted for household size, people's income falls as soon as they have children.

Once I have controlled for the presence of children, living in a household with a larger number of adults reduces the risk of being persistently below the poverty line, as estimated coefficients imply higher exit rates and lower re-entry rates. This is likely to be related to the higher potential earnings (e.g. a working spouse) or incomes (e.g. a living-in grandmother with her pension) that the household can enjoy when there are additional adults who are willing to share their resources within the household. Using both the coefficients of "number of children in the household" and of the "number of adults", I calculate that an adult aged 30 living as a couple without children has an exit rate after one year of about $56 \%$, while the corresponding figure if there are three children is $66 \%$. For the same individual, the re-entry rate after one year out of poverty is $32 \%$ with three children and only $19 \%$ without.

Whether or not the household head is female does not seem to affect the exit probabilities. This finding is at variance with what suggested by previous research on the UK (e.g., OECD, 1998) and, even more, with what reported by Stevens (1999) in her US 
sample. ${ }^{17}$ However female headship seems to be an important determinant of the re-entry probabilities: a single mother in her thirties has a re-entry rate at duration one about $26 \%$ higher than a single father. ${ }^{18}$

In one version of my model 1 (not shown) ethnicity appeared to negatively affect exit rates when it is introduced in the form a non-white dummies (grouping together AfroCaribbean, Indian, Pakistani, others) but no significant relation was found in the case of reentry rates. However, separate dummies for each ethnic group turned out to be non significant.

Finally, the local unemployment rate is found to have a negative impact on the exit rates, while it is not significant for re-entry rates. ${ }^{19}$ After one year in poverty, a thirty-yearold single person travelling to work in an area with a low unemployment rate (say 3\%) has an exit rate $26 \%$ higher than if s/he worked in a high unemployment area (say with unemployment at $12 \%)$.

Model 2 in Table 6 illustrates that controlling for unobserved heterogeneity does produce relevant differences in the reported estimates, compared to the model without unobserved heterogeneity. In many cases, the coefficient size becomes larger in absolute value, so that the impact of regressors on the chances of leaving and re-entering poverty is amplified. However, once we control for unobserved heterogeneity, the evidence in favour of negative duration dependence is to some extent reduced, as some duration dummies lose their statistical significance. This is often the case in duration models and may be taken as an indication that the duration dependence, rather than indicating a true 'scarring' or 'state dependence' effect, might be spurious and most likely due to the omission of unobserved heterogeneity (see, for instance, Kiefer (1988)).

Table 7.a reports the estimated distribution and support points of the individualspecific error terms for $\theta^{P}$ and $\theta^{N}$. About $77 \%$ of individuals are estimated to have a high unobserved tendency of exiting and a low tendency to re-enter (type 2). The remaining 23\% of persons have a higher than average persistence, with lower exit rates and higher re-entry rates (type 3). The data did not support the presence of the other two types (type 1 and 4) as

\footnotetext{
${ }^{17}$ One of the reason might be that in the PSID terminology a female head is equivalent to a single female head of household, while this is not necessarily the case in the BHPS.

${ }^{18}$ This calculation requires also the use of the coefficient of the 'number of adults' (=1 in this case).
} 
the respective probabilities are estimated to be zero. ${ }^{20}$ If we could know which unobserved heterogeneity group an individual belonged to, then we would be able to compare the hazard rates of individuals who are otherwise observationally equivalent. For example, we have reported above that the exit rate after one year for a well-educated single adult aged 30 is 0.64. If we knew that this person belonged to the group with low exit tendency (type 3) we would have to also include the estimated unobserved heterogeneity parameter $\theta^{P}=-1.64$ when computing the hazard rate, as in (2). Then the probability of leaving poverty after one year for these individual would reduce to 0.21 only. Given the relatively high size of the estimated individual-specific error terms, it should not come as a surprise that individuals with adverse unobserved heterogeneity values are at a substantially higher risk of persistent poverty.

Finally, I briefly discuss the result reported in Model 3 of Table 6. To identify the parameters of the initial condition equation (4) I have used pre-sample information (Heckman, 1981), and in particular information about the parental background of the household head when s/he was 14. Dummy indicators for whether the father of the household head was dead, and if not, whether he was working, have been introduced. Analogous indicators for the mother of the household head - when the head was 14 - are also included. Cappellari and Jenkins (2002) use similar indicators to identify their initial condition equations. Though these variables are statistically significant, we note that the random effect $q$ entering the initial condition equation is not (see Table 7.b). ${ }^{21}$ Moreover many probabilities $R_{k}$ had to be constrained to be zero in order to achieve convergence. While the difficulties in fitting this model could well be a signal that it is computationally too demanding for our relatively short panel data set, one might also speculate that in our data there is no initial condition problem. This is because whether the first fresh spell is a poverty or a non-poverty one does not seem to be correlated with the future chances of

\footnotetext{
${ }^{19}$ Calendar year dummies were considered, for controlling the impact of aggregate economic conditions, but found to be scarcely significant.

${ }^{20}$ The model was initially estimated with six support points, but it did not converge indicating that the data would not allow such a general specification for the unobserved heterogeneity distribution. Then the model was re-estimated with four support points and probabilities, as explained in the appendix. Once again convergence difficulties indicated that some of the probabilities $R_{k}$ had to be constrained to zero.

${ }^{21}$ I also experimented with information related to the occupation of the father and mother of the household head (when this was 14) to estimate the initial condition equation, but $q$ remained not significant.
} 
exiting or re-entering poverty. Though through a different approach, Stevens (1999) reached the conclusion that dropping left-censored spells was immaterial for her results.

My final comments concern the reported standard errors, as there are reasons to believe that they may be too small, making regressor coefficients statistically significant even when they might be not. This may arise from both the BHPS sample design and, more importantly, for the fact that I use multiple individuals from the same household, so that observations within the household are not independent. Stevens computes 'corrected' standards errors using the half-sample replication technique and reports that the new standard errors are considerably higher than the unadjusted ones. ${ }^{22}$ As half-sample variables are not available in the BHPS, this method cannot be applied here. I limit myself to the consideration that my estimates are highly statistically significant and, presumably, would remain so even with larger standard errors. Nevertheless, the search for more satisfactory ways of dealing with this problem constitutes a challenge for future research.

\subsection{Predicting poverty experiences: the implications of the estimates.}

So far I have only illustrated how estimated hazard rates change for individuals who differ in one characteristic, keeping constant the others. However, what is more interesting is the estimate of the distribution of total time spent poor over multiple spells for individuals who differ in more than one characteristic. In this section I therefore employ microsimulation techniques in an attempt to draw out implications for individuals' future poverty experience under different scenarios. Such exercises are illuminating for policy, particularly when the different scenarios can be interpreted as the outcome of alternative policy intervention schemes. Stevens (1999), Moffitt and Rendall (1995) and Gottschalk and Moffitt (1994) inspire the following analysis.

The logit hazard rates specified above can be expressed in terms of the underlying latent index function:

$$
I_{i}^{k}=\theta_{i}^{k}+\alpha_{i}^{k}+\beta^{k} X_{i t}+\varepsilon^{k}
$$

\footnotetext{
22 This technique is computationally demanding, basically requiring that one's models be re-estimated numerous times on re-sampled data. Stevens' hazard rate models are weighted using the PSID sample weights, given that the PSID - originally over-sampling low-income households - is not a random sample. Both this weighting and the PSID clustered sample design constitute reasons for the need to correct traditional standard errors, which may be even more important than the non-independence of observations. Arguably, these additional sources of bias are less of a problem for the BHPS (see Taylor, 1998).
} 
where $I_{i}^{k}, k=P, N$, is a latent variable such that an exit from state $k$ occurs if $I^{k}>0$; otherwise the individual survives in the state. The error terms are assumed to be distributed independently and to follow the logistic distribution.

I first created an artificial database (cohort) of 10,000 individuals, each observed for 8 years, whose initial age, sex of the household head, education of the household head, etc., are pre-specified. One can then use the estimates for $\theta^{k}, \alpha^{k}$ and $\beta^{k}$ reported in Table 6 to generate values for $I^{k}$ for each person-year. Model 2 is a natural candidate as the "preferred model" and is the one used in these simulations. Values for $\varepsilon^{k}$ are randomly drawn from the logistic density function and the vector $\left(\theta^{P}{ }_{i}, \theta^{N}{ }_{i}\right)$ that describes the individual unobservedability for each of the 10,000 individuals (for their entire lifetime) is drawn from the discrete distribution with the estimated support points and probability (Table 7.a). The individuals are assumed to be in poverty at the first interview and exit at the first next person-year in which $I^{P}>0$. In that case they start an out-of-poverty spell which concludes whenever $I^{N}>0$, so that a new poverty spell starts thereafter.

The 8-wave poverty status sequence is so generated for each individual, and the sensitivity to different set of assumptions about the starting individual characteristics can be assessed. Results are displayed in Table 8. Each row of the left panel in the table represents a combination of individual and household characteristics for which we are interested in estimating the total time spent below the poverty line. For each of these combinations, 10,000 individuals starting a poverty spell are artificially generated, as explained above, assuming that the selected characteristics (with the exception of age) are kept constant in each year of the simulation period. The information on the 10,000 individuals is then used to compute the 'mean time in poverty over the next 7 years' and the 'proportion of the cohort spending more than 4 years poor out of the next 7 '. This is done for each row of Table 8 and the results are shown in the first two columns in the right-hand side panel.

The first row in Table 8 depicts the case of a child born in poverty (age 0 ), who lives in a household headed by single-parent woman with low education, with a total of three children and in an area with an unemployment rate as high as $15 \%$. As one might expect, poverty is a particularly persistent phenomenon for this child. My hazard rate models predict that the 'expected number of years in poverty over the next 7 interviews' is as high as 5.3, and the 'proportion of the cohort who are poor for more than 4 years out of the next 
$7^{\prime}$ is about $73 \%$. Were the same child be living in a male-headed household (row 2) the corresponding figures would have dropped to 5.1 and $69 \%$, respectively. As the number of children present in the household falls, poverty persistence drops correspondingly. Things get relatively better also if the household moves to an area where the local unemployment is at $7 \%$ or at $3 \%$. An only-child living with his/her lowly educated father in an area with good job opportunities (row 5) is expected to spend 3.7 years below the poverty line. Persistence in poverty is further reduced as the number of adults in the households grows, and in fact row 6 shows that only $22 \%$ of the only-child persons born poor remain so for more than 4 out of seven years if there are two living-in adults. The additional effect of living in a household where the head is highly educated is given in row 7. In this case 2.9 is the expected number of years below the poverty line and the proportion of poor for at least four years declines to $18 \%$. Finally, row 8 considers a 'best' possible scenario for a child: living with both parents and an additional adult, with a male well-educated head, with no other children, and in low-unemployment area. Only $12 \%$ of these children spend at least four years in poverty.

From row 9 onward, the sensitivity of poverty persistence with respect to individual age is illustrated, by considering the cases of individuals aged 24 (rows 9-16), aged 40 (row 17-25), aged 60 (rows 26-31), and finally aged 75. At a rapid glance, a U-pattern of poverty persistence with respect to age is revealed, although differences between the various age groups are quite small. Children and the elderly appear to be more at risk of spending a large number of years below the poverty line, while those aged 40 face better prospects of avoiding prolonged periods of deprivation. Even persons in their forties are not immune from the problem, though, especially so if they have many children and live in single-adult households.

\section{A VARIANCE-COMPONENTS APPROACH TO THE MEASUREMENT OF POVERTY PERSISTENCE}

\subsection{Estimating the time-series process of income}

In this section I use an alternative modelling approach for deriving poverty persistence predictions. Using components-of-variance models, I first estimate the parameters of a time series process describing income dynamics. Next, the estimated parameters are used to 
derive statements about poverty persistence and these are then compared to the estimates obtained with the hazard rate models. The importance of such an exercise is twofold. On the one hand, it is relevant in its own right, as a way of comparing the performance of two alternative modelling approaches to poverty dynamics. On the other, it can be seen as a means of assessing the robustness of the findings reported earlier.

Lillard and Willis (1978) were the first to apply a variance-components approach to the study of poverty dynamics. While they focused on earnings dynamics and its implications for low-pay dynamics (see also Abowd and Card, 1989; Baker, 1997; Dickens, 2000; Ramos, 1999; Cappellari, 2000), more recent applications have used the log of 'net household equivalent income' as their dependent variable (for instance, Duncan and Rodgers, 1991; Stevens, 1999; Biewen, 2002). The estimation method is a generalised method-of-moments approach, which minimises the distance between the sample covariances and their population counterparts. An important characteristic of this approach is that it avoids the (somewhat arbitrary) assumption of normality of the variance components usually invoked by maximum likelihood approaches to their estimation.

Various models describing household income are used, each having different implications for the population (theoretical) covariance structure. First, suppose that the evolution of the household income over time can be summarised by the following equation:

$$
Y_{i t}=X_{i t} \beta+U_{i t}
$$

where $Y_{i t}$ is the log of equivalent-household-net-income, $X_{i t}$ contains terms for age and years effect (and potentially other variables). The residual term $U_{i t}$ can be specified according to alternative and increasingly general models. A fairly general specification that embeds simpler ones as special cases is where $U_{i t}$ consists of a weighted sum of a personspecific component $\left(\mu_{i}\right)$ and a transitory term $v_{i t}$ assumed to follow a process with a firstorder autoregressive term and a first-order moving average term, $\operatorname{ARMA}(1,1)$, so that: ${ }^{23}$

$$
\begin{aligned}
& U_{i t}=\delta_{t} \mu_{i+} \lambda_{t} v_{i t} \\
& v_{i t} \rho v_{i t-1}+\varepsilon_{i t+} \varphi \varepsilon_{i t-1}
\end{aligned}
$$

where $\mu_{i} \sim\left(0, \sigma_{\mu}{ }^{2}\right), \varepsilon_{i t} \sim\left(0, \sigma_{\varepsilon}{ }^{2}\right), \rho$ and $\varphi$ are parameters and $\delta_{t}, \lambda_{t}$ are weighting factors. ${ }^{24}$

\footnotetext{
${ }^{23}$ Higher order ARMA processes were considered too, but rejected by the data.

${ }^{24}$ Variation over time in the permanent and transitory components is achieved through these weighting factors, which are allowed to vary each year. One way to interpreting them is to think of the term $\mu_{i}$ as a proxy for ability and the term $\delta_{t}$ as the return to this ability (e.g., Dickens, 2000).
} 
The model summarised by (6)-(8) implies a particular form for the population covariances of $U_{i t}$, whose elements can be expressed as functions of the underlying parameters to be estimated, as well as of additional parameters coming from the initial condition treatment suggested by McCurdy (1982). ${ }^{25}$ These expressions are derived in various papers, so I do not replicate them here (e.g., Ramos, 1999). By the assumptions made, the residual $U_{i t}$ is uncorrelated across individuals, but is serially correlated for each individual. Estimation of the parameters of interest proceeds by minimising the "distance" between these population moments and their empirical counterparts (GMM or minimum distance estimation). ${ }^{26}$ These in turn are formed from the residuals of a first-stage regression of $Y_{i t}$ on year dummies, age, age squared, as well as education and sex of the household head, number of adults and number of children in the household and local unemployment rate. All these explanatory variables were introduced in the first-stage OLS regression for comparison with the hazard model results. ${ }^{27}$ The sample used is the same as for the hazard rate models so as to achieve comparability of the predictions obtained with both approaches. ${ }^{28}$ The estimated covariance matrix is included in the appendix as Table 9. This table shows an increase in the cross-sectional variances over time, particularly from 1996, and a substantial persistence in the covariance terms at higher orders.

The estimated parameters of the error structure are shown in Table 10. In the first model presented (column 1), the error term in (6) is simply supposed to be an unweigthed $\operatorname{sum}\left(\delta_{t}=\lambda_{t}=1\right.$, for each $\left.t\right)$ of an individual random effect and a transitory term that follows a white noise process. The estimated variance of the permanent component $\left(\sigma_{\mu}{ }^{2}\right)$ and of the temporary component $\left(\sigma_{\varepsilon}^{2}\right)$ imply that permanent differences between the individuals

\footnotetext{
${ }^{25}$ By introducing a small number of additional parameters into the analysis, McCurdy (1982) proposed a parameterisation of the autocovariances that treats initial conditions as random variables and assumes that these conditions are themselves generated by the ARMA processes one is fitting to the data. Following his equation (13), expressions for the transitory error term for period $t=1$ (start of the panel) - and therefore for its variance - can be derived, as a function of these additional parameters. However, I have also experimented with a simpler treatment of the initial condition - i.e. simply letting the variance of $v_{i l}$ at $t=1$ be a constant to be estimated - and got very similar results to those with the more complete treatment suggested by McCurdy.

${ }^{26} \mathrm{I}$ used the consistent but asymptotically inefficient equally-weighted minimum distance estimator, which has been commonly used in the literature instead of the optimally-weighted estimator. See the technical appendix in Dickens (2000) for a clear, albeit concise, exposition of the estimation methodology used.

${ }^{27}$ Regression coefficients are constrained to be equal across years. Formal hypothesis tests easily accept this restriction at conventional levels.

${ }^{28}$ Stevens (1999) restricted her sample to a balanced panel of adults between the age of 24 and 64 . While there are reasons to do so when estimating earnings equations, it is less obvious that a similar practice should be followed when studying needs-adjusted household income dynamics.
} 
explain about $51 \%$ of total variation in first-stage residuals. A well-known shortcoming of this simple model is that it predicts constant correlation for the disturbances in different years. However the empirical covariance matrix I estimated in Table 9 suggests that the correlation between residual incomes decreases at larger temporal distances. In order to replicate such a pattern, one can assume that some serial correlation is present in the transitory component. The second column in Table 10 then specifies the transitory component in $U_{i t}$ as an $\operatorname{AR}(1)$ process, which is clearly a special case of (8) with $\varphi=0$. The first-order correlation coefficient, $\rho$, is equal to 0.54 indicating that transitory shocks are not very persistence: only $16 \%$ of a shock is still present after 3 years. This value of $\rho$ is lower than what reported by Stevens, which might be partly explained by the different samples she used as explained above (footnote 27). Permanent income differences now account for only $31 \%$ of the (stationary) variance of $U_{i t}$.

One problem with the $\mathrm{AR}(1)$ model is that it predicts constant variances over time, while my estimated covariance matrix shows that variances have - to some extent - been increasing over time. A simple way to accommodate the non-stationarity of the variances is to allow weighting parameters $\delta_{t}, \lambda_{t}$ to assume different values at each different time period. ${ }^{29}$ This is accomplished in the model reported in column 3, whose estimates however are not very different from those of the previous model. There is some evidence that the permanent component $\mu$ has attracted higher returns $(\delta)$ over time, particularly so until 1996, while the weight of the transitory component $(\lambda)$ does not seem to have changed much. Ramos (1999) concludes that this is the model that best fits the covariance matrix of log-earnings for the first half of the 1990s in the UK.

Finally a specification in which the transitory term $v_{i t}$ follows a $\operatorname{ARMA}(1,1)$ was estimated in column (4). Measurement error in this model will come through this transitory component. The correlation coefficient $\rho$ is now equal to 0.76 indicating a higher persistence of transitory shocks than before. The negative MA component (-0.267) implies that the auto-covariances decline sharply over the first period, while reducing slower at longer gaps. The goodness-of-fit $\chi^{2}$ statistics shown at the bottom of the table indicates that model (4) slightly outperforms the other models. 
In the literature on the dynamics of earnings an alternative specification to the one in (6)-(8) has sometimes been employed (e.g., Backer, 1997). This case is often referred to as "random-growth model" because the individual permanent component in (6) is specified through an individual-specific intercept and an individual-specific slope. ${ }^{30}$ As Table 10 shows, the variance of the individual-specific slope term in the random-growth model is statistically insignificant. On this evidence I discard the random-growth model as a model capable of explaining needs-adjusted household income dynamics in the UK over the 1990s.

\subsection{Implications For Poverty And Comparison With The Hazard-Rate Models}

Once one of the models estimated in Table 10 has been selected as a good representation of my data, I can then use its parameter estimates to derive the expected time spent below the poverty line for individuals with selected characteristics. Following Stevens, I generate the $(\log )$ household equivalent net income for 8 years of each of 10,000 individuals, assumed to start at the same given age and to with the same pre-specified characteristics (held constant throughout the simulation period). Therefore, knowing $X_{i t}$ and using the estimated $\beta$, I can simulate $Y_{i t}$ in (6) by simply drawing $U_{i t}{ }^{31}$ To do so, I assume that $\varepsilon_{i t}$ and $\mu_{i}$ are normally distributed, with zero mean and with the estimated variances in Table 10. For these microsimulations I have used estimates from both model (3) and (4) and found that they produced almost indistinguishable results.

Next, I identify all those individuals that, according to their simulated income, enter poverty for the first time at wave 2 . These individuals are then followed for the next 7 years (including wave 2) and the number of times they have been poor is counted. This way, I can compute the distribution of time spent poor for those just beginning a poverty spell, as I did with the hazard rate models, and can compare predictions obtained with both approaches. The 'mean years in poverty over the next 7 years' and the 'proportion poor for

\footnotetext{
${ }^{29}$ Another possibility would be to allow the transitory term $v_{i t}$ to have year-specific variances. I was unable to get convergence when Model 2 was so extended.

${ }^{30}$ In the "random-growth model" the individual permanent component in (6) is specified such that $U_{i t}=\delta_{t}\left(\mu_{i}\right.$ $+\phi_{i}$ age $\left._{i t}\right)+\lambda_{t} v_{i t}$. Here $\mu_{i}$, an individual-specific intercept, and $\phi_{i}$, an individual-specific slope, are random variables. Additional parameters to be estimated are $\operatorname{var}(\mu)=\sigma_{\mu}{ }^{2}, \operatorname{var}(\phi)=\sigma_{\phi}{ }^{2}$ and $\operatorname{cov}(\mu, \phi)=\sigma_{\mu \phi}$.

${ }^{31}$ These simulations hold business cycle conditions constant at the average of the calendar year terms from the first-stage regression in (6).
} 
more than 4 waves' obtained through the variance-components models are reported in the last two columns of Table 8.

A glance at the last four columns of the table shows that the ranking of the various groups of the population in terms of either the 'mean years in poverty over the next 7 years' or the 'proportion poor for more than 4 waves' is the same with both the hazard rate models and the variance components models. As for the relative magnitude of the two set of estimates, there does not seem to be a clear-cut pattern. The hazard rate models seem to produce slightly higher values for the individuals with less favourable characteristics in each age group (save the oldest age group) than the variance-components models. For example, expected time poor was 5.3 in row 1 or 4.9 in row 9 with the hazard models and, respectively, 5.0 and 3.9 with the variance components models. For more favourable characteristics differences are somewhat smaller (see in particular the predictions at age 40, rows 17-25). A bit surprising is the result that - after rounding to one digit - a larger number of adults does not have any visible impact in reducing poverty persistence (the estimated coefficient of 'number of adults' in the first-stage regression was positive and significant but small), while had the expected effect in the hazard-rate models. More generally, as we consider different combinations of characteristics, the simulated results obtained with the variance-components models exhibit less variability than those derived from the hazard rate models. This may be related to the fact that the hazard-rate models focus on the population at risk of poverty transitions (near the poverty threshold), while the variance components apply to all person, rich and poor, assuming that the income dynamics process is the same. Changes in the value of household characteristics (e.g. a rise in the number of adults) may then have a more immediate impact on the chances of crossing the threshold in the hazard-rate approach, compared to the variance components models where the effect on the poverty transitions is mediated via the estimated household income process.

Notwithstanding this, in many cases the predictions delivered by the two approaches are surprisingly close (e.g., rows 5, 7, 14, 21, 29, 35). The implication that one may be tempted to draw is a reassuring one: my poverty persistence rankings, and - to a lesser extent - my measurements, seem to be robust to the choice of the modelling strategy. 
Ideally one would like to derive conclusions about the relative performance of the two approaches in terms of their ability to replicate observed poverty patterns for the targeted subgroups. Unfortunately, this is a much harder task to accomplish. Stevens in her tables comparing the predictions of the two approaches also reported estimates of poverty persistence obtained from directly tabulating the total time poor for a cohort of people observed to enter poverty at wave 2, and followed up for the next 6 interviews. She writes that "the hazard rate and direct tabulations are generally consistent with one another, while the variance components model produces slightly different distributions" (page 580). However, an obvious problem with this method is the small sample size for certain groups of the population, particularly when one is controlling for a relatively large set of observables. That prevented in this paper any assessment about the relative performance of the hazard rate and components-of-variance approaches to be based on a comparison with the direct tabulations only. ${ }^{32}$

At an "average" level, though, there is some evidence that my variance-components models perform slightly worse than my multiple-spells hazard models in replicating the observed poverty pattern in the data. In column 5 of Table 5 (both panel $a$ and $b$ ) I have simulated the distribution of time poor using my preferred variance-components model, holding characteristics at their sample means. ${ }^{33}$ A comparison of the two measures of poverty persistence reported at the bottom of each panel of the table justifies the claim. By necessity further research is called for in order to devise feasible ways to assess the 'goodness' of the alternative approaches to poverty dynamics.

\section{CONCLUSIONS}

This paper has provided new evidence on low-income dynamics for individuals living in Britain in the 1990s. Using waves 1-8 of the BHPS, it has investigated how persistent is poverty when measured over repeated spells. The importance of assessing the time spent

\footnotetext{
${ }^{32}$ For example, in my data there are only 46 individuals who are observed entering poverty at wave two and living in a household headed by a woman with low education, in each of the next 6 years. For demographic groups constructed on the basis on all the covariates introduced in my models sample sizes would easily become even smaller. The different size of the US PSID, as well as her different specification, permitted Stevens (1999) to carry out these comparisons.

${ }^{33}$ Very similar results were obtained if the error components used in the simulation were re-estimated from individual incomes netted out only of each year's mean income. Simulated incomes were the sum of the year's average plus the simulated permanent and transitory components.
} 
poor by an individual over a fixed time window, rather than over the first poverty spell only, has been stressed, given that about $30 \%$ of those just ending a poverty spell are estimated to be again below the poverty line within one year. My results show that while only $19 \%$ of the population is predicted to spend at least 4 years in poverty out of 7 in single poverty spells, the figure becomes a striking $41 \%$ when allowing for repeated spells.

Using a hazard-rate multivariate-modelling framework, the paper has shown that there are groups of the population that not only are systematically more at risk of falling below the poverty line, they are also more likely to remain below it for a much longer number of years. Children constitute a particularly striking example of persons with a high risk of persistent poverty. When they live in a single-parent household headed by a woman with low education they can end up spending in poverty a number of years that is more than twice that of a 40-year old, well-educated living as a childless couple. More generally, persons living in a household with relatively many children and few adults, headed by a person with low education, who is a woman, and travelling to work in areas with higher local unemployment rates, are those for whom hardship can be a prolonged phenomenon. The young and the elderly also face relatively high risks of remaining poor for long periods.

My result complement early hazard-rate applications for Britain by controlling for correlated unobserved heterogeneity and by further pursuing the multiple-spell approach to the measurement of poverty persistence. Unobserved individual heterogeneity was found to be important too, with $77 \%$ of my sample having unobserved characteristics that keeps them out of poverty, while there is a $23 \%$ of less lucky individuals whose unobserved characteristics constrain them below the poverty line. Duration dependence is also at play, even though its importance is reduced after controlling for unobserved characteristics.

The paper has also attempted to extend Stevens' model to account for endogeneity in the first state. The data did not support the initial condition equation, providing hints that the standard practise of dropping left-censored spells might not have dramatic implications for the parameter estimates. The issue however needs be further investigated, for example by taking advantage of future releases of the BHPS.

Predictions of poverty persistence obtained through hazard rate models and variancecomponents models were also compared. In many cases this provided evidence that estimates were robust. Though for the population as a whole the variance-components 
models seemed to perform worse in terms of its ability to replicate the poverty patterns emerging from the data, future research should further investigate the relative performance of the two approaches for targeted population subgroups. The assumption that the same income dynamics process applies to all person might be relaxed and the effect of sample attrition on the results may be addressed.

The policy implications stressed by previous research (importance the labour market conditions, secondary earners in the household, income supplement for non-working households, early identification and intervention for the recurrently and persistently poor, as well as targeted measures aimed at increasing exit rates and reducing entry rates) may find additional support in the results of this paper.

\section{REFERENCES}

Abowd J and Card D (1989), "On The Covariance Structure Of Earnings And Hours Changes", Econometrica, 57(2), pp 411-45.

Allison PD (1982), Discrete-Time Methods For The Analysis Of Event Histories. In Sociological Methodology, ed. S. Leinhardt, 61-97. San Francisco: Jossey-Bass Publishers.

Atkinson AB, Bourguignon F, Morrisson C (1992) "Empirical Studies Of Earnings Mobility". Harwood Academic Publishers, Chur CH.

Baker M (1997), "Growth Rate Heterogeneity And The Covariance Structure Of Earnings” Journal Of Labour Economics 15(2): 411-45.

Bane MJ, Ellwood DT (1986), "Slipping Into And Out Of Poverty: The Dynamics Of Spells”. Journal Of Human Resources: 21, 1-23.

Bardasi E, Jenkins SP And Rigg J (1999), "Documentation For Derived Current And Annual Net Household Income Variables, BHPS Waves 1-7”, ISER Working Paper 9925. http://www.iser.essex.ac.uk/pubs/workpaps/index.php.

Böheim R, Jenkins SP (2000), “Do Current Income And Annual Income Measures Provide Different Pictures Of Britain's Income Distribution?”, ISER Working Paper 2000-16. Böheim R, Taylor M (2000), “Unemployment Duration And Exit States In Britain”, ISER Working Paper 2000-1. http://www.iser.essex.ac.uk/pubs/workpaps/index.php. 
Burgess S, Propper C (1998), “An Economic Model Of Household Income Dynamics, With An Application To Poverty Dynamics Among American Women”. Discussion Paper No. 1830, Centre For Economic Policy Research, London.

Cappellari L (2000), “The Covariance Structure Of Italian Male Wages”, The Manchester School, 68, 659-684.

Cappellari L and Jenkins SP (2002a), "Who Stays Poor? Who Becomes Poor? Evidence From The British Household Panel Survey", The Economic Journal, 112, C60-C66.

Cappellari L and Jenkins SP (2002b), "Modelling Low Income Transitions?, ISER Working Papers, No. 2002-8, Essex University, Colchester.

Biewen M. (2002), “The Covariance Structure of East and West German Incomes and its Implications for the Persistence of Poverty and Inequality", IZA DP No. 459. Downloadable from: www.iza.org

Cantó Sanchez O (1998), “The Dynamics Of Poverty In Spain: The Permanent And The Transitory Poor”. Unpublished Paper, European University Institute, Florence.

Department Of Social Security (1999), Households Below Average Income 1979-1994/5. The Stationery Office, London.

Devicienti F (2001), "Poverty Persistence In Britain: A Multivariate Analysis Using The BHPS, 1991-1997’, In P. Moyes, C. Seidl And A.F. Shorrocks (Eds), Inequalities: Theory, Measurement And Applications, Journal Of Economics, Suppl. 9, 1-34. Downloadable as ISER WP, 2001-02. http://www.iser.essex.ac.uk/pubs/workpaps.

Dickens R (2000), “The Evolution Of Individual Male Earnings In Great Britain: 1975-95”, The Economic Journal, 110, pp 27-49.

Duncan GJ, Rodgers W (1988), "Longitudinal Aspects Of Child Poverty". Journal Of Marriage And The Family, 50: 1007-1021.

Duncan GJ, Rodgers W (1991), “Has Child Poverty Become More Persistent?” American Sociological Review, 56: 538-550.

Duncan GJ, Coe RD, Hill MS (1984), “The dynamics of poverty”. In: Duncan GJ, Coe RD, Corcoran ME, Hill MS, Hoffman SD, Morgan JN (eds), Years of poverty, years of plenty: the changing economic fortunes of American workers and families. Institute for Social Research, University of Michigan, Ann Arbor MI. 
Flinn C, Heckman J (1983), “Are Unemployment And Out-Of-The-Labour-Force Behaviourally Distinct Force States?", Journal Of Labour Economics, 1, 28-42.

Gottschalk P, Moffitt R (1994), "Welfare Dependence: Concepts, Measures, And Trends". American Economic Review (Papers And Proceedings) 84: 38-42.

Greene W (2000), Econometric Analysis, Forth Edition, Prentice Hall International, Inc.

Ham JC, Lalonde RJ (1996), “The Effect Of Sample Selection And Initial Conditions In

Duration Models: Evidence From Experimental Data On Training”, Econometrica, 64, No. 1, pp 175-205.

Heckman J (1981), “The Incidental Parameter Problem And The Problem Of Initial Conditions In Estimating A Discrete Time-Discrete Data Stochastic Process", In Mansky C, McFadden D, Eds., Structural Analysis Of Discrete Data With Econometric Applications. Cambridge, MA: MIT Press, pp. 179-95.

Heckman J, Singer B (1984), “A Method For Minimising The Impact Of Distributional Assumptions In Econometric Models Of Duration Data”, Econometrica, 52, 271-320.

Hill MS, Jenkins SP (1997), "Poverty Amongst British Children: Permanent Or Transitory?”, In Bradbury B, Jenkins SP, Micklewright J (Eds) The Dynamics of Child Poverty in Industrialised Countries. Cambridge University Press. Cambridge.

Jarvis S, Jenkins SP (1997), “Low Income Dynamics In 1990s Britain”. Fiscal Studies 18: 120.

Jarvis S, Jenkins SP (1998), “How Much Income Mobility Is There In Britain?” Economic Journal 108: 428-443.

Jenkins SP (1997), "Discrete Time Proportional Hazard Regression". Stata Technical Bulletin, STB-39, 22-23. Reprinted in Stata Technical Bulletin, vol. 8, ed. H.J. Newton, pp 269-274, 1999. College Station TX: Stata Corporation.

Jenkins SP (1995), "Easy Estimation Methods For Discrete-Time Duration Models”. Oxford Bullettin Of Economics And Statistics, 57, 1, pp 129-37.

Jenkins SP (2000), "Modelling Household Income Dynamics", Journal Of Population Economics, 13 (4).

Kiefer N. (1988), "Econometric Analysis Of Duration Data". Journal Of Economic Literature, 26, pp. 646-679. 
Lillard LA, Willis RJ (1978), "Dynamic Aspects Of Earnings Mobility”. Econometrica 46: 985-1012.

Lancaster T. (1990), The Econometric Analysis Of Transition Data. Cambridge University Press: Cambridge.

Macurdy T (1982), "The Use Of Time Series Processes To Model The Error Structure Of Earnings In Longitudinal Data Analysis", Journal Of Econometrics 18: 83-114.

Meghir C, Whitehouse E (1997), "Labour Market Transitions And Retirement Of Men In The UK", Journal Of Econometrics.

Meyer BD (1990), "Unemployment insurance and unemployment spells". Econometrica, 58 (4), 757-782.

Moffitt R, Rendall M (1984), "Cohort Trends In The Lifetime Distribution Of Female Family Headship In The US, 1968-1985”, Demography, 32(4), pp 407-24.

OECD (1998), "Low-income dynamics in four OECD countries", OECD Economic Outlook, chapter VI, 171-185.

Ondrich J, Rhody S (1999), "Multiple spells in the Prentice-Gloeckler-Meyer likelihood with unobserved heterogeneity". Economics Letters, 63, 139-144.

Prentice R, Gloecker L (1978), "Regression analysis of grouped survival data with application to breast cancer data". Biometrics, 34, 57-67.

Ramos X (1999) “The Covariance Structure Of Earnings In Great Britain: 1991-1995, ISER Working Paper 99-4. http://www.iser.essex.ac.uk/pubs/workpaps/index.php.

Schluter C (1997) "On The Non-Stationarity Of German Income Mobility (And Some Observations On Poverty Dynamics)". DARP Discussion Paper No. 30, STICERD, London School Of Economics, London.

Stevens A Huff (1999) "Climbing Out Of Poverty, Falling Back In: Measuring The Persistence Of Poverty Over Multiple Spells". Journal Of Human Resources: XXXIV, (34)3, 557-588.

Taylor A (1994) “Appendix: Sample Characteristics, Attrition And Weighting”. In: Buck N, Gershuny J, Rose D, And Scott J (Eds) Changing Households: The British Household Panel Survey 1990-1992. ESRC Research Centre On Micro-Social Change, University Of Essex, Colchester. 
Taylor MF (Ed) (1998) "British Household Panel Survey User Manual: Introduction,

Technical Reports And Appendices”. ESRC Research Centre On Micro-Social Change,

University Of Essex, Colchester. URL: http://www.iser.essex.ac.uk/bhps

Walker R With Ashworth K (1994) Poverty Dynamics: Issues And Examples. Avebury, Aldershot.

\section{APPENDIX}

\section{A.1 Technical appendix: Estimation of the multiple-spell model of transitions in and out of poverty with and without the initial condition (models 2 and 3 of Table 6).}

When correlated random effect terms are entered in the hazard specifications, exiting from one state cannot be treated a priori as independent conditional on the observables: the poverty and non-poverty spells cannot be treated separately. Individuals flowing into one state are an endogenously selected sub-sample of the whole population. To deal with this problem we need to specify the likelihood function for all the transitions for any individual in the data and integrate out the random effects. The likelihood function for this model is given by this general expression (see Meghir and Whitehouse, 1997):

$$
\begin{aligned}
\mathrm{L}= & \sum_{i=1}^{N} \log \int_{H\left(\theta^{P}\right)} \int_{H\left(\theta^{N}\right)} \int_{H(q)} L_{i}\left(\theta^{P}, \theta^{N}, q\right) \cdot d G\left(\theta^{P}, \theta^{N}, q\right) ; \\
L_{i}\left(\theta^{P}, \theta^{N}, q\right)= & P_{i 0}(q)^{v_{i 0}}\left(1-P_{i 0}(q)\right)^{u_{i 0}} \mathrm{x} \\
& \prod_{j=1}^{J_{i}-1}\left[\left(1-E_{i j}\left(\theta^{P}\right)\right)^{1-y_{i t}} \cdot E_{i j}\left(\theta^{P}\right)^{y_{i t}}\right]^{v_{i t}} \cdot\left[\left(1-B_{i j}\left(\theta^{N}\right)\right)^{1-y_{i t}} \cdot B_{i j}\left(\theta^{N}\right)^{y_{i t}}\right]^{u_{i t}} .
\end{aligned}
$$

Here $L_{i}\left(q, \theta_{i}^{P}, \theta_{i}^{N}\right)$ denotes individual's $i$ contribution to the likelihood function, conditional to the unobserved heterogeneity terms. $H(q), H\left(\theta^{P}\right)$ and $H\left(\theta^{N}\right)$ denote the supports of, respectively, $q, \theta^{P}$ and $\theta^{N} . J_{i}$ is the total number of interviews in which individual $i$ has been observed in the panel, excluding years in left-censored spells. The subscript $j$ indexes the sequence of poverty outcomes of each individual $i$, and $j=0$ refers to the time in which his/her first non-left censored spell started. The variable $u_{i j}$ takes value 1 if the spell at $j$ is a poverty spell otherwise it takes value 0 . Similarly, $v_{i j}$ is a dummy variable taking value 1 if the spell at $j$ is a non-poverty spell, otherwise it is 0 . Finally, $y_{i j}$ is a dummy variable equal to 1 if the person exit from the current state in $j$, otherwise is zero. 
In the spirit of Heckman and Singer, the unobserved heterogeneity distribution $G\left(q, \theta^{P}\right.$, $\left.\theta^{N}\right)$ is left unspecified and is approximated by a trivariate discrete distribution, with $q, \theta^{P}$ and $\theta^{N}$ assuming each a finite number of support points. When this number is equal to two for each random variable, the joint distribution $G$ is as in Figure 1, with 6 support points and 8 corresponding probabilities. The integrals in the above likelihood function are then replaced by summations over this finite number of support points. The overall loglikelihood function is then maximised with respect to all the model parameters: $\beta^{k}, \alpha_{d}^{k}$, and the support points of $q$ and $\theta^{k}, k=P, N$, along with the probabilities $R_{j}, j=1, \ldots, 8$. Inference is done conditional to the number of support points. As I include a full set of duration dummies in the hazard specification (2) and (3), one support point of each unobserved heterogeneity variables has been normalised to zero. Finally, it should be noted that the method proposed by Heckman-Singer method to approximate $G\left(q, \theta^{P}, \theta^{N}\right)$ requires that the number of support points of the approximating trivariate discrete distribution be determined by the data, rather than a priori. In practise, this means that one should maximise the likelihood function successively with increasing numbers of support points for $q, \theta^{P}$ and $\theta^{N}$, until the criterion function does not change much any more and the parameters remain relatively stable. This has been the route followed, though the generalised versions of Figure 1 are not shown in the interest of brevity.

\section{Figure 1}

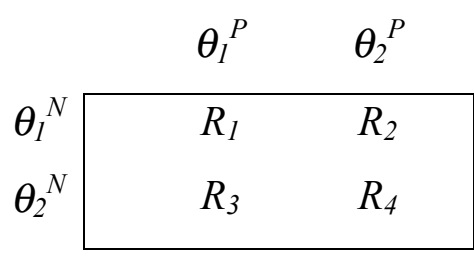

$q=q_{1}$

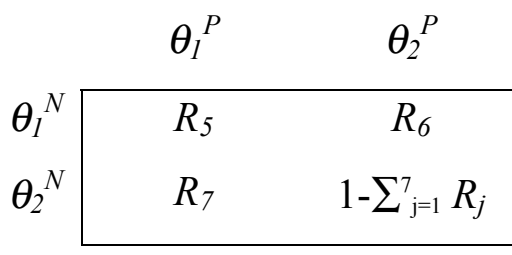

$q=q_{2}$

In model 2 of Table 6 , the likelihood contribution of the individual $i$ is simplified, as there is no initial condition equation. In this case, the individual's likelihood contribution is written conditional only on $\theta^{P}$ and $\theta^{N}$. For each individual these can be collected in the vector $\boldsymbol{\theta}_{i}=\left(\theta_{i}^{P}, \theta_{i}^{N}\right)$. If $\theta^{P}$ and $\theta^{N}$ are assumed to take on two support points each, their joint distribution is a simplified version of figure 1 , consisting of four probabilities only, $R_{j}$, 
$j=1, \ldots, 4$. Given that the vector $\boldsymbol{\theta}_{i}$ can take any of four possible combinations (four personal types), we write the unconditional contribution of individual $i$ as:

$$
L_{i}=R_{1} L_{i}\left(\boldsymbol{\theta}_{i 1}\right)+R_{2} L_{i}\left(\boldsymbol{\theta}_{i 2}\right)+R_{3} L_{i}\left(\boldsymbol{\theta}_{i 3}\right)+R_{4} L_{i}\left(\boldsymbol{\theta}_{i 4}\right) .
$$

This is the expression reported by Stevens (1999) and the number of parameters to be estimated is reduced correspondingly.

\section{A.2 Tables}

Table 1: Trends in mean income and poverty

\begin{tabular}{|c|c|c|c|c|c|c|c|c|}
\hline & 1991 & 1992 & 1993 & 1994 & 1995 & 1996 & 1997 & 1998 \\
\hline $\begin{array}{l}\text { Mean } \\
\text { Needs-adjusted } \\
\text { Household net income }\end{array}$ & 14285 & 14565 & 14747 & 14654 & 15143 & 15238 & 15325 & 15819 \\
\hline $1991=100$ & 100.0 & 102.0 & 103.2 & 102.6 & 106.0 & 106.7 & 107.3 & 110.7 \\
\hline $\begin{array}{l}\% \text { of poor } \\
\text { (absolute poverty line) } \\
\% \text { of poor } \\
\text { (relative poverty line) }\end{array}$ & 15.7 & 16.6 & 17.0 & 16.2 & 14.9 & 14.5 & 14.7 & 13.3 \\
\hline "n. persons & 111634 & 11001 & 10475 & 10477 & 10128 & 10544 & 10556 & 10384 \\
\hline
\end{tabular}

Table 1 is based on an unbalanced sample of persons (adult and children) in complete respondent household for all waves for which they are in the sample. The poverty line is half wave 1 mean income. Income is household net equivalent income. BHPS cross sectional enumerated weights have been used to account for differential nonresponse rates (see Taylor, 1998, chapter V, vol. A, for details). 
Table 2: Number of waves in poverty

\begin{tabular}{ccc} 
& Absolute poverty line & Relative poverty line \\
\cline { 2 - 3 } $\begin{array}{c}\text { Number of interviews } \\
\text { in poverty }\end{array}$ & Percent poor & Percent poor \\
\hline 0 & 68.3 & 66.3 \\
1 & 13.5 & 13.6 \\
2 & 6.9 & 7.4 \\
3 & 3.8 & 4.1 \\
4 & 2.7 & 2.8 \\
5 & 1.7 & 2.1 \\
6 & 1.5 & 1.6 \\
7 & 1.1 & 1.2 \\
8 & 0.5 & 0.7 \\
\hline & 100 & 100 \\
\hline Total number of persons & & 16531 \\
\hline \hline
\end{tabular}

The absolute poverty line is half mean wave 1 income. The relative one is half contemporaneous mean income.

Table 3: Survivor function and exit rates from poverty, for all persons beginning a poverty spell (KaplanMeier estimates)

(a) absolute poverty line

\begin{tabular}{|c|c|c|c|c|c|}
\hline \multirow[t]{2}{*}{$\begin{array}{l}\text { Number of interviews } \\
\text { since start poverty spell }\end{array}$} & \multirow[t]{2}{*}{$\begin{array}{c}\text { Number at risk of exit at start } \\
\text { of period }\end{array}$} & \multirow[t]{2}{*}{$\begin{array}{l}\text { Survivor } \\
\text { Function }\end{array}$} & \multicolumn{3}{|c|}{ Exit rates } \\
\hline & & & (s.e.) & & (s.e.) \\
\hline 1 & 2592 & 1 & & 0.50 & 0.014 \\
\hline 2 & 1037 & 0.50 & 0.010 & 0.41 & 0.020 \\
\hline 3 & 512 & 0.30 & 0.009 & 0.34 & 0.026 \\
\hline 4 & 236 & 0.19 & 0.009 & 0.22 & 0.031 \\
\hline 5 & 121 & 0.15 & 0.009 & 0.13 & 0.033 \\
\hline 6 & 37 & 0.13 & 0.009 & 0.30 & 0.152 \\
\hline 7 & 26 & 0.09 & 0.012 &. & . \\
\hline
\end{tabular}

(b) relative poverty line

\begin{tabular}{cccccc}
$\begin{array}{c}\text { Number of interviews } \\
\text { since start poverty spell }\end{array}$ & $\begin{array}{c}\text { Number at risk of exit at start } \\
\text { of period }\end{array}$ & $\begin{array}{c}\text { Survivor } \\
\text { Function }\end{array}$ & Exit rates & (s.e.) \\
\hline \hline 1 & 2798 & 1 &. & 0.47 & 0.013 \\
2 & 1172 & 0.53 & 0.009 & 0.37 & 0.018 \\
3 & 591 & 0.33 & 0.010 & 0.32 & 0.023 \\
4 & 282 & 0.23 & 0.009 & 0.18 & 0.025 \\
5 & 163 & 0.19 & 0.009 & 0.16 & 0.031 \\
6 & 52 & 0.16 & 0.009 & 0.25 & 0.070 \\
7 & 39 & 0.12 & 0.012 &. &. \\
\hline
\end{tabular}

Lifetable estimates based on all non-left censored poverty spells, pooled from the BHPS waves 1-8. Standard errors in parenthesis. 
Table 4: Survivor function and poverty re-entry rates, for all persons ending a poverty spell (Kaplan-Meier estimates)

(a) absolute poverty line

\begin{tabular}{|c|c|c|c|c|c|}
\hline $\begin{array}{l}\text { Number of interviews } \\
\text { since start non-poverty } \\
\text { spell }\end{array}$ & $\begin{array}{l}\text { Number at risk of re-entry at } \\
\text { start of period }\end{array}$ & $\begin{array}{l}\text { Survivor } \\
\text { Function }\end{array}$ & (s.e.) & $\begin{array}{l}\text { Re-entr } \\
\text { rates }\end{array}$ & (s.e.) \\
\hline 1 & 2522 & 1 & . & 0.29 & 0.011 \\
\hline 2 & 1445 & 0.71 & $(0.009)$ & 0.16 & 0.011 \\
\hline 3 & 914 & 0.59 & $(0.010)$ & 0.10 & 0.010 \\
\hline 4 & 599 & 0.53 & $(0.011)$ & 0.10 & 0.013 \\
\hline 5 & 338 & 0.48 & $(0.012)$ & 0.09 & 0.017 \\
\hline 6 & 163 & 0.43 & $(0.013)$ & 0.04 & 0.016 \\
\hline 7 & 156 & 0.41 & $(0.014)$ & . & . \\
\hline
\end{tabular}

(a) relative poverty line

\begin{tabular}{cccccc}
$\begin{array}{c}\text { Number of interviews } \\
\text { since start non-poverty } \\
\text { spell }\end{array}$ & $\begin{array}{c}\text { Number at risk of re-entry at } \\
\text { start of period }\end{array}$ & $\begin{array}{c}\text { Survivor } \\
\text { Function }\end{array}$ & Re-entry \\
rates & (s.e.) \\
\hline \hline 1 & 2536 & 1 &. & 0.32 & 0.011 \\
2 & 1368 & 0.67 & 0.009 & 0.18 & 0.011 \\
3 & 847 & 0.55 & 0.010 & 0.13 & 0.012 \\
4 & 539 & 0.48 & 0.011 & 0.10 & 0.013 \\
5 & 298 & 0.43 & 0.012 & 0.14 & 0.021 \\
6 & 145 & 0.37 & 0.013 & 0.12 & 0.028 \\
7 & 128 & 0.33 & 0.015 &. &. \\
\hline \hline
\end{tabular}

Lifetable estimates based on all non-left censored non-poverty spells, pooled from the BHPS waves 1-8. Standard errors in parenthesis. 
Table 5: Distribution of the 'Number of interviews with low income out of the next 7' for the cohort of people just starting a poverty spell at the second interview.

\section{a. Absolute poverty line}

\begin{tabular}{|c|c|c|c|c|}
\hline \multirow[b]{2}{*}{$\begin{array}{l}\text { Number of interviews } \\
\text { In poverty }\end{array}$} & \multicolumn{3}{|c|}{$\begin{array}{l}\text { Hazard-rate } \\
\text { approach }\end{array}$} & \multirow[t]{2}{*}{$\begin{array}{c}\text { Variance- } \\
\text { components } \\
\text { approach }\end{array}$} \\
\hline & $\begin{array}{l}\text { Single } \\
\text { Spell }\end{array}$ & $\begin{array}{l}\text { Repeated } \\
\text { Spell }\end{array}$ & Actual & \\
\hline 1 & 49.6 & 21.6 & 18.6 & 26.1 \\
\hline 2 & 20.8 & 20.2 & 19.8 & 21.0 \\
\hline 3 & 10.1 & 17.0 & 16.8 & 16.7 \\
\hline 4 & 4.3 & 13.1 & 19.3 & 13.6 \\
\hline 5 & 1.9 & 9.5 & 7.4 & 9.9 \\
\hline 6 & 4.0 & 9.4 & 11.4 & 8.1 \\
\hline \multirow[t]{2}{*}{7} & 9.2 & 9.2 & 6.6 & 4.8 \\
\hline & 100 & 100 & 100 & 100 \\
\hline $\begin{array}{l}\text { mean years poor } \\
\text { over next } 7 \text { years }\end{array}$ & 2.37 & 3.34 & 3.37 & 2.99 \\
\hline $\begin{array}{c}\% \text { poor } 4+\text { years } \\
\text { (out of next } 7 \text { ) }\end{array}$ & 19 & 41 & 45 & 36 \\
\hline
\end{tabular}

\section{b. Relative poverty line}

\begin{tabular}{|c|c|c|c|c|}
\hline \multirow[b]{2}{*}{$\begin{array}{l}\text { Number of interviews } \\
\text { In poverty }\end{array}$} & \multicolumn{3}{|c|}{$\begin{array}{c}\text { Hazard-rate } \\
\text { approach }\end{array}$} & \multirow[t]{2}{*}{$\begin{array}{c}\text { Variance- } \\
\text { components } \\
\text { approach }\end{array}$} \\
\hline & $\begin{array}{c}\text { Single } \\
\text { Spell }\end{array}$ & $\begin{array}{l}\text { Repeated } \\
\text { Spell }\end{array}$ & Actual & \\
\hline 1 & 47.3 & 17.8 & 14.3 & 24.8 \\
\hline 2 & 19.4 & 18.4 & 18.1 & 21.0 \\
\hline 3 & 10.5 & 16.3 & 14.8 & 17.5 \\
\hline 4 & 4.1 & 13.7 & 15.6 & 13.7 \\
\hline 5 & 3.0 & 11.1 & 13.8 & 10.7 \\
\hline 6 & 3.9 & 11.0 & 13.6 & 7.5 \\
\hline \multirow[t]{2}{*}{7} & 11.7 & 11.7 & 9.8 & 4.8 \\
\hline & 100 & 100 & 100 & 100 \\
\hline $\begin{array}{l}\text { mean years poor } \\
\text { over next } 7 \text { years }\end{array}$ & 2.54 & 3.62 & 3.77 & 3.06 \\
\hline $\begin{array}{l}\% \text { poor } 4+\text { years } \\
\text { (out of next } 7 \text { ) }\end{array}$ & 23 & 48 & 53 & 37 \\
\hline
\end{tabular}

Column 2 and 3 (and 5 and 6, for the relative poverty line) are derived from the exit and re-entry rates in Tables 3 and 4 . Column 4 and 7 derives from wave 2 low-income entry cohort (sequences 01 xxxxxx in Table 2 , where $x=0,1)$. The first column refers to the total number of years in poverty (i.e. the number of interviews with low income, including the one in which the poverty spell started (at wave 2). 
Table 6: Poverty exit and re-entry rates regressions

\begin{tabular}{|c|c|c|c|c|c|c|}
\hline \multirow{3}{*}{$\begin{array}{l}\text { Unobserved heterogeneity } \\
\text { Initial condition }\end{array}$} & \multicolumn{2}{|c|}{ model 1} & \multicolumn{2}{|c|}{ model 2} & \multicolumn{2}{|c|}{ model 3} \\
\hline & \multicolumn{2}{|c|}{ NO } & \multicolumn{2}{|c|}{ YES } & \multicolumn{2}{|c|}{ YES } \\
\hline & \multicolumn{2}{|c|}{ NO } & \multicolumn{2}{|c|}{ NO } & \multicolumn{2}{|c|}{ YES } \\
\hline & Coef. & $\mathbf{Z}$ & Coef. & $\mathbf{z}$ & Coef. & $\mathbf{z}$ \\
\hline \multicolumn{7}{|l|}{ (a) poverty } \\
\hline \multicolumn{7}{|l|}{ Duration dummies } \\
\hline 1 & 0.198 & 1.250 & 0.726 & 2.400 & 0.657 & 2.030 \\
\hline 2 & -0.140 & -0.820 & 0.592 & 1.680 & 0.547 & 1.420 \\
\hline 3 & -0.488 & -2.620 & 0.450 & 1.140 & 0.395 & 0.910 \\
\hline 4 & -1.009 & -4.410 & 0.037 & 0.080 & 0.021 & 0.040 \\
\hline 5 & -1.565 & -4.910 & -0.442 & -0.880 & -0.330 & -0.590 \\
\hline 6 & -0.715 & -1.610 & 0.540 & 0.870 & 0.476 & 0.690 \\
\hline head has A-levels or more & 0.147 & 1.750 & 0.157 & 1.510 & 0.201 & 1.830 \\
\hline no. of children in the hh & -0.146 & -4.520 & -0.196 & -4.690 & -0.204 & -4.670 \\
\hline no. of adults in the hh & 0.233 & 4.850 & 0.272 & 4.600 & 0.352 & 5.190 \\
\hline local unemployment rate & -0.053 & -3.790 & -0.069 & -3.890 & -0.072 & -3.810 \\
\hline
\end{tabular}

\section{(b) non-poverty}

Duration dummies
1

2

3

4

5

6

Age/100

Age /100 squared

Female headship

Head has A-levels or more

No. of children in the hh

No. of adults in the hh

$\begin{array}{cc}-0.577 & -3.260 \\ -1.247 & -6.650 \\ -1.840 & -8.910 \\ -1.796 & -8.030 \\ -1.706 & -6.700 \\ -2.588 & -6.070 \\ -0.971 & -1.830 \\ 1.349 & 2.220 \\ 0.348 & 4.770 \\ -0.237 & -2.980 \\ 0.243 & 7.180 \\ -0.368 & -6.790\end{array}$

$1.461 \quad 2.420$

$0.954 \quad 1.510$

$0.263 \quad 0.410$

$0.351 \quad 0.540$

$0.454 \quad 0.670$

$-0.984 \quad-1.120$

$-4.444 \quad-3.650$

$4.455 \quad 3.770$

$0.340 \quad 3.510$

$-0.233-2.130$

0.269

5.790

$-0.433$

$-6.390$
1.575

1.072

0.418

0.363

0.609

$-0.768$

$-4.578$

4.449

0.347

$-0.305$

0.284

$-0.520$
2.360

1.510

0.570

0.480

0.780

$-0.790$

$-3.260$

3.360

3.440

$-2.600$

5.760

$-6.750$

\section{(c) Initial condition}

Father of hh head dead

Father of hh head in work

Mother of hh head dead

Mother of hh head in work

No. of children in the hh

No. of adults in the hh

constant

$\begin{array}{cc}0.637 & 2.360 \\ 0.358 & 2.390 \\ -0.628 & -2.080 \\ 0.225 & 2.000 \\ -0.097 & -2.110 \\ -0.170 & -2.710 \\ 0.624 & 3.290\end{array}$

Table 6 continues over 
Likelihood:

Poverty equation $\quad-2064$

Non-poverty equation $\quad-2693$

Both equations jointly

$-3939$

$-4862$

Observations:

Poverty equation

Non-poverty equation

5973

Both equations jointly

7556

7431

Notes: (logit coefficients). In model 1, exit rate and re-entry rate equations are estimated separately. In model 2 (and model 3), the two equations are estimated jointly. Model 3 also includes the initial condition equation.

Table 7: Estimated unobserved heterogeneity distribution

(a) Model 2

\begin{tabular}{|c|c|c|c|c|}
\hline & $\theta^{P}$ & $\theta^{N}$ & $\begin{array}{c}\text { obability } \\
\left(R_{i}\right)\end{array}$ & s.e. ${ }^{\S}$ \\
\hline Type 1 & Low & Low & $0^{*}$ & \\
\hline Type 2 & high & Low & 0.77 & 0.110 \\
\hline Type 3 & low & High & 0.23 & 0.110 \\
\hline \multirow[t]{2}{*}{ Type 4} & High & high & $0^{*}$ & 列 \\
\hline & & & 1.00 & \\
\hline
\end{tabular}

\section{Support points}

\begin{tabular}{lccrcc} 
& $\theta^{P}$ & s.e. & & $\theta^{N}$ & s.e. \\
\cline { 2 - 3 } \cline { 5 - 5 } Low & -1.642 & 0.299 & & -1.464 & 0.406 \\
High & $0^{\wedge}$ & $\cdot$ & & $0^{\wedge}$ & $\cdot$
\end{tabular}

continue 
(b) Model 3

\begin{tabular}{|c|c|c|c|c|c|}
\hline & $\theta^{P}$ & $\theta^{N}$ & $q$ & $\begin{array}{c}\text { Probability } \\
\left(R_{j}\right)\end{array}$ & s.e. ${ }^{\S}$ \\
\hline Type 1 & Low & Low & Low & $0^{*}$ & . \\
\hline Type 2 & Low & High & Low & 0.02 & 0.027 \\
\hline Type 3 & High & Low & Low & 0.74 & 0.111 \\
\hline Type 4 & High & High & Low & $0^{*}$ & . \\
\hline Type 5 & Low & Low & High & $0^{*}$ & . \\
\hline Tyре 6 & Low & High & High & 0.24 & 0.102 \\
\hline Type 7 & High & Low & High & $0^{*}$ & \\
\hline \multirow[t]{2}{*}{ Type 8} & High & High & High & $0^{*}$ & . \\
\hline & & & & 1.00 & \\
\hline
\end{tabular}

\section{Support points}

\begin{tabular}{|c|c|c|c|c|c|c|}
\hline & $\theta^{P}$ & s.e. & $\theta^{N}$ & s.e. & $q$ & s.e. \\
\hline Low & -1.687 & 0.298 & -1.377 & 0.444 & -15.66 & 397.35 \\
\hline High & $0^{\wedge}$ & . & $0^{\wedge}$ & . & $0^{\wedge}$ & . \\
\hline
\end{tabular}

Notes:

* The probabilities $R_{k}$ were constrained to lie in the $(0,1)$ interval and to sum to one using the logistic transformation $R_{k}=\exp \left(-r_{k}\right) /\left(1+\Sigma_{i=l}^{4} \exp \left(-r_{k}\right)\right)$ and estimating the parameters $r_{k}$.

${ }^{\S}$ The standard errors of $R_{k}$ have been derived from the standard errors of the $r_{k}$ using the delta method (see for instance Greene, 2000).

One support point for each unobserved heterogeneity variable has been normalised to zero. 
Table 8: Simulation results: expected years in poverty for individuals with selected characteristics

\begin{tabular}{|c|c|c|c|c|c|c|c|c|c|c|}
\hline \multirow[b]{2}{*}{ Row } & \multicolumn{6}{|c|}{ Household and individual characteristics } & \multicolumn{2}{|c|}{ Hazard models } & \multicolumn{2}{|c|}{$\begin{array}{l}\text { Variance-components } \\
\text { models }\end{array}$} \\
\hline & $\begin{array}{c}\text { Individual } \\
\text { age }\end{array}$ & $\begin{array}{c}\text { Sex of } \\
\text { household } \\
\text { head }\end{array}$ & $\begin{array}{c}\text { Education of } \\
\text { household } \\
\text { head }\end{array}$ & $\begin{array}{l}\text { number } \\
\text { of adults } \\
\text { in househ. }\end{array}$ & $\begin{array}{l}\text { Number } \\
\text { of children } \\
\text { in househ. }\end{array}$ & $\begin{array}{c}\text { Local } \\
\text { unemployment } \\
\text { rate } \\
\end{array}$ & $\begin{array}{l}\text { Mean years } \\
\text { Poor over the } \\
\text { Next } 7 \text { years }\end{array}$ & $\begin{array}{l}\text { \% poor more } \\
\text { than } 4 \text { years } \\
\text { out of the } \\
\text { next } 7\end{array}$ & $\begin{array}{l}\text { Mean years } \\
\text { Poor over the } \\
\text { Next } 7 \text { years } \\
\end{array}$ & $\begin{array}{c}\text { \% poor more } \\
\text { than } 4 \text { years } \\
\text { out of the } \\
\text { next } 7\end{array}$ \\
\hline 1 & 0 & female & low & 1 & 3 & high & 5.3 & 73 & 5.0 & 64 \\
\hline 2 & 0 & male & low & 1 & 3 & high & 5.1 & 69 & 4.8 & 58 \\
\hline 3 & 0 & male & low & 1 & 1 & High & 4.4 & 51 & 4.0 & 43 \\
\hline 4 & 0 & male & low & 1 & 1 & medium & 3.9 & 37 & 3.7 & 36 \\
\hline 5 & 0 & male & low & 1 & 1 & low & 3.7 & 31 & 3.6 & 33 \\
\hline 6 & 0 & male & low & 2 & 1 & low & 3.2 & 22 & 3.6 & 33 \\
\hline 7 & 0 & male & high & 2 & 1 & low & 2.9 & 18 & 3.0 & 22 \\
\hline 8 & 0 & male & high & 3 & 1 & low & 2.5 & 12 & 3.0 & 22 \\
\hline 9 & 24 & female & low & 1 & 3 & high & 4.9 & 63 & 3.9 & 41 \\
\hline 10 & 24 & male & low & 1 & 3 & high & 4.7 & 58 & 3.9 & 36 \\
\hline 11 & 24 & male & low & 1 & 1 & high & 4.0 & 42 & 3.1 & 24 \\
\hline 12 & 24 & male & low & 1 & 1 & medium & 3.4 & 29 & 2.9 & 19 \\
\hline 13 & 24 & male & low & 1 & 1 & low & 3.2 & 24 & 2.8 & 18 \\
\hline 14 & 24 & male & low & 2 & 1 & low & 2.7 & 17 & 2.8 & 18 \\
\hline 15 & 24 & male & high & 2 & 1 & low & 2.4 & 14 & 2.1 & 8 \\
\hline 16 & 24 & male & high & 2 & 0 & low & 2.2 & 11 & 1.9 & 8 \\
\hline 17 & 40 & female & low & 1 & 3 & high & 4.8 & 60 & 3.9 & 39 \\
\hline 18 & 40 & male & low & 1 & 3 & high & 4.6 & 55 & 3.6 & 33 \\
\hline 19 & 40 & male & low & 1 & 1 & high & 3.8 & 39 & 3.1 & 23 \\
\hline 20 & 40 & male & low & 1 & 1 & low & 3.0 & 22 & 2.6 & 14 \\
\hline 21 & 40 & male & low & 2 & 3 & low & 3.2 & 25 & 3.3 & 27 \\
\hline 22 & 40 & male & high & 2 & 3 & low & 2.9 & 21 & 3.0 & 16 \\
\hline 23 & 40 & male & high & 2 & 1 & low & 2.3 & 13 & 2.0 & 9 \\
\hline 24 & 40 & male & high & 2 & 0 & low & 2.1 & 10 & 1.8 & 5 \\
\hline 25 & 40 & male & high & 3 & 0 & low & 1.8 & 6 & 1.8 & 5 \\
\hline 26 & 60 & female & low & 1 & 3 & high & 4.8 & 61 & 4.4 & 50 \\
\hline 27 & 60 & male & low & 1 & 3 & high & 4.6 & 56 & 4.2 & 44 \\
\hline 28 & 60 & male & low & 1 & 0 & high & 3.7 & 36 & 3.2 & 26 \\
\hline 29 & 60 & male & low & 2 & 0 & high & 3.0 & 25 & 3.2 & 26 \\
\hline
\end{tabular}


Table 8, continue

\begin{tabular}{|c|c|c|c|c|c|c|c|c|c|c|}
\hline 30 & 60 & male & high & 2 & 0 & high & 2.8 & 20 & 2.4 & 10 \\
\hline 31 & 60 & male & high & 2 & 0 & low & 2.1 & 10 & 2.1 & 10 \\
\hline 32 & 75 & female & low & 1 & 0 & high & 3.9 & 39 & 4.2 & 46 \\
\hline 33 & 75 & male & low & 1 & 0 & high & 3.7 & 35 & 4.0 & 42 \\
\hline 34 & 75 & female & high & 1 & 0 & high & 3.5 & 33 & 3.5 & 33 \\
\hline 35 & 75 & male & high & 1 & 0 & high & 3.3 & 30 & 3.4 & 30 \\
\hline 36 & 75 & male & high & 2 & 0 & high & 2.9 & 22 & 3.4 & 30 \\
\hline 37 & 75 & male & high & 2 & 0 & low & 2.2 & 11 & 2.9 & 18 \\
\hline
\end{tabular}

Simulations for 10,000 individuals just starting a poverty spell with pre-specified characteristics. High education refers to A-levels or more. High unemployment rate is set at $15 \%$, medium at $8 \%$ and low at $3 \%$. With the exception of age, each characteristic is held fixed at the specified value in each year of the simulation period. 
Table 9: Estimated covariance matrix of needs-adjusted household-net-income residuals

\begin{tabular}{|c|c|c|c|c|c|c|c|c|}
\hline & 1991 & 1992 & 1993 & 1994 & 1995 & 1996 & 1997 & 1998 \\
\hline \multirow[t]{2}{*}{1991} & 0.224 & 0.154 & 0.131 & 0.123 & 0.112 & 0.108 & 0.101 & 0.101 \\
\hline & $(0.011)$ & $(0.007)$ & $(0.006)$ & $(0.007)$ & $(0.006)$ & $(0.006)$ & $(0.006)$ & $(0.006)$ \\
\hline \multirow[t]{2}{*}{1992} & 0.695 & 0.220 & 0.164 & 0.145 & 0.133 & 0.128 & 0.120 & 0.122 \\
\hline & & $(0.009)$ & $(0.007)$ & $(0.007)$ & $(0.007)$ & $(0.006)$ & $(0.007)$ & $(0.006)$ \\
\hline \multirow[t]{2}{*}{1993} & 0.578 & 0.728 & 0.230 & 0.173 & 0.152 & 0.146 & 0.135 & 0.142 \\
\hline & & & $(0.011)$ & $(0.008)$ & $(0.007)$ & (0.009) & $(0.008)$ & $(0.008)$ \\
\hline \multirow[t]{2}{*}{1994} & 0.529 & 0.628 & 0.736 & 0.240 & 0.184 & 0.162 & 0.152 & 0.148 \\
\hline & & & & $(0.015)$ & $(0.011)$ & $(0.008)$ & $(0.008)$ & $(0.007)$ \\
\hline \multirow[t]{2}{*}{1995} & 0.494 & 0.590 & 0.659 & 0.776 & 0.232 & 0.182 & 0.164 & 0.154 \\
\hline & & & & & $(0.013)$ & $(0.008)$ & $(0.007)$ & $(0.007)$ \\
\hline \multirow[t]{2}{*}{1996} & 0.473 & 0.558 & 0.627 & 0.674 & 0.777 & 0.235 & 0.190 & 0.171 \\
\hline & & & & & & $(0.012)$ & $(0.010)$ & $(0.010)$ \\
\hline \multirow[t]{2}{*}{1997} & 0.420 & 0.499 & 0.546 & 0.600 & 0.661 & 0.763 & 0.265 & 0.200 \\
\hline & & & & & & & $(0.015)$ & $(0.012)$ \\
\hline \multirow[t]{2}{*}{1998} & 0.421 & 0.507 & 0.572 & 0.584 & 0.620 & 0.685 & 0.751 & 0.266 \\
\hline & & & & & & & & $(0.015)$ \\
\hline
\end{tabular}

Notes: Covariance matrix of first-stage OLS residuals of log needs-adjusted household net income on year dummies, age, age squared, education and sex of the household head, number of adults and number of children in the household and local unemployment rate. Above the diagonal entries are covariances between indicated years; below the diagonal entries are correlation coefficients. Standard errors in parenthesis (forth moment matrix). 
Table 10: Estimated Variance components

\begin{tabular}{|c|c|c|c|c|c|}
\hline \multirow[t]{2}{*}{$\begin{array}{l}\text { Permanent } \\
\text { component }\end{array}$} & \multicolumn{4}{|c|}{$\mu_{i}$} & \multirow{2}{*}{$\begin{array}{c}\mu_{i}+\gamma_{i} \text { age }_{i t} \\
(5)\end{array}$} \\
\hline & (1) & (2) & (3) & (4) & \\
\hline $\begin{array}{l}\text { Transitory } \\
\text { Component }\end{array}$ & $\begin{array}{l}\text { White } \\
\text { Noise }\end{array}$ & $\mathrm{AR}(1)$ & $\operatorname{AR}(1)$ & $\operatorname{ARMA}(1,1)$ & $\mathrm{AR}(1)$ \\
\hline$\sigma_{\mu}^{2}$ & $\begin{array}{c}0.150 \\
(4184)\end{array}$ & $\begin{array}{c}0.107 \\
(0799)\end{array}$ & $\begin{array}{c}0.079 \\
(1545)\end{array}$ & $\begin{array}{l}0.083 \\
(848)\end{array}$ & $-0.106^{\S}$ \\
\hline$\sigma_{\gamma}^{2}$ & $(41.84)$ & $(21.99)$ & (15.4J) & & $\begin{array}{l}(-0.23) \\
0.0001 \\
(0.20)\end{array}$ \\
\hline$\sigma_{\mu \gamma}$ & & & & & $\begin{array}{l}0.0005 \\
(0.03)\end{array}$ \\
\hline$\sigma_{\varepsilon}^{2}$ & $\begin{array}{c}0.144 \\
(30.08)\end{array}$ & $\begin{array}{c}0.137 \\
(27.03)\end{array}$ & $\begin{array}{c}0.129 \\
(12.86)\end{array}$ & $\begin{array}{c}0.185 \\
(16.09)\end{array}$ & $\begin{array}{c}0.161 \\
(22.14)\end{array}$ \\
\hline$\rho$ & & $\begin{array}{c}0.540 \\
(34.13)\end{array}$ & $\begin{array}{c}0.419 \\
(28.66)\end{array}$ & $\begin{array}{c}0.760 \\
(19.12)\end{array}$ & $\begin{array}{c}0.527 \\
(16.00)\end{array}$ \\
\hline$\varphi$ & & & & $\begin{array}{c}-0.267 \\
(-10.20)\end{array}$ & \\
\hline$\Psi_{I C}$ & & $\begin{array}{c}0.126 \\
(14.13)\end{array}$ & $\begin{array}{c}0.177 \\
(18.65)\end{array}$ & $\begin{array}{c}0.165 \\
(12.61)\end{array}$ & $\begin{array}{c}0.567 \\
(12.56)\end{array}$ \\
\hline $\begin{array}{c}\text { Loading } \\
\text { factors }\end{array}$ & NO & NO & YES & NO & NO \\
\hline SSR & 0.035 & 0.006 & 0.001 & 0.002 & 0.006 \\
\hline$\chi^{2}$ & 607 & 179 & 74 & 68 & 201 \\
\hline DF & 34 & 28 & 19 & 31 & 31 \\
\hline
\end{tabular}

Estimated loading factors (model 3 only)

\begin{tabular}{ccccccc}
\hline \hline$\delta_{2}$ & $\delta_{3}$ & $\delta_{4}$ & $\delta_{5}$ & $\delta_{6}$ & $\delta_{7}$ & $\delta_{8}$ \\
1.152 & 1.218 & 1.318 & 1.372 & 1.376 & 1.291 & 1.289 \\
$(31.36)$ & $(25.12)$ & $(24.75)$ & $(22.67)$ & $(23.38)$ & $(22.58)$ & $(23.22)$ \\
& & & & & & \\
$\lambda_{2}$ & $\lambda_{3}$ & $\lambda_{4}$ & $\lambda_{5}$ & $\lambda_{6}$ & $\lambda_{7}$ & $\lambda_{8}$ \\
1 & 1.070 & 1.002 & 1.079 & 0.979 & 1.100 & 1.006 \\
$\cdot$ & $(21.14)$ & $(18.84)$ & $(17.50)$ & $(17.28)$ & $(17.67)$ & $(19.30)$ \\
\hline \hline
\end{tabular}

Below each coefficient I have reported the $\mathrm{t}$ statistics in brackets. The weights $\delta_{1}, \lambda_{1}, \lambda_{2}$ have been normalised to 1 , so as to insure identification of the model. DF denoted the degrees of freedom of the $\chi^{2}$ goodness-of-fit statistics. See Dickens (1999), technical appendix, for explanations.

$\S$ When I re-estimated the model in column (5) with the constraint that $\sigma_{\mu}{ }^{2}$ be positive I failed to get convergence.

$\Psi_{I C}$ refers to the first period variance, as explained in footnote 24. 